\title{
AEROSSÓIS, NUVENS E CLIMA: RESULTADOS DO EXPERIMENTO LBA PARA O ESTUDO DE AEROSSÓIS E MICROFÍSICA DE NUVENS
}

\author{
ALEXANDRE ARAÚJO COSTA ${ }^{1,2}$ E THEOTONIO PAULIQUEVIS ${ }^{3}$ \\ ${ }^{1}$ Universidade Estadual do Ceará, Departamento de Física - Fortaleza/CE ,Brasil \\ ${ }^{2}$ Fundação Cearense de Meteorologia e Recursos Hídricos, (FUNCEME). \\ ${ }^{3}$ Instituto Astronômico, Geofísico e de Ciências Atmosféricas, (IAG) - São Paulo, Brasil \\ alex@funceme.br, theo@model.iag.usp.br
}

Recebido Julho 2008 - Aceito Maio 2009

\begin{abstract}
RESUMO
Os aerossóis atmosféricos respondem por uma das maiores incertezas na investigação dos cenários de mudança climática. A margem de erro associada às estimativas nas contribuições dos aerossóis no balanço energético global ainda é elevada, particularmente no que diz respeito ao chamado "efeito indireto". Ainda que o nível de compreensão científico, acerca do efeito indireto tenha avançado significativamente nos últimos anos, este ainda é muito baixo, quando comparado com o entendimento que se tem do papel dos gases de efeito estufa. Particularmente no Brasil, as medidas realizadas dentro do contexto LBA-SMOCC-EMfiN! (Large-Scale Biosphere-Atmosphere Experiment in Amazonia - Smoke Aerosols, Clouds, Rainfall and Climate - Experimento de Microfísica de Nuvens) possibilitaram uma base de dados ampla sobre aerossóis e microfísica de nuvens. Neste trabalho, apresentamos uma revisão de alguns dos principais resultados relacionados a essa base de dados, tanto via análise de resultados experimentais, quanto via modelagem numérica. Conclui-se que alterações significativas no processo de desenvolvimento da precipitação podem ocorrer em associação com a grande quantidade de aerossóis produzidos em queimadas, mas que diversas questões, principalmente referentes ao papel dos núcleos de condensação gigantes e núcleos de gelo ainda precisam ser elucidadas.
\end{abstract}

Palavras-chave: Aerossóis, microfísica de nuvens, LBA

\begin{abstract}
AEROSOLS, CLOUDS AND CLIMATE: RESULTS FROM LBA ON AEROSOLS AND CLOUD MICROPHYSICS STUDIES.

Atmospheric aerosols account for some of the largest uncertainties regarding climate change scenarios. The uncertainties associated to the estimates of the aerosol contributions in the global energy budget is still very high, particularly concerning the so-called "indirect effect". Hence, although the level of scientific understanding on the role of aerosols in climate have advanced significantly in the last few years, it is still very low in comparison to the well established knowledge concerning the effect of greenhouse gases. Particularly in Brazil, the measurements taken during the LBA-SMOCC-EMfiN! (Large-Scale Biosphere-Atmosphere Experiment in Amazonia - Smoke Aerosols, Clouds, Rainfall and Climate - Experimento de Microfísica de Nuvens) provided a comprehensive data base on aerosols and cloud microphysics. In this work, we review some of the major results related to such data base, via both analysis of experimental data and numerical modeling. We conclude that significant changes in precipitation development may occur in association with the large amount of aerosols launched into the atmosphere by forest fires but that several questions, especially those ones concerning giant cloud condensation nuclei and ice nuclei, have to be clarified.
\end{abstract}

Keywords: Aerosols, cloud microphysics, LBA 


\section{INTRODUÇÃO}

As atividades antrópicas têm sido responsáveis por mudanças substanciais no ambiente do planeta, principalmente a partir do início da era industrial, o que inclui até mesmo a composição química da atmosfera do planeta (Vitousek et al., 1997). Há consenso na comunidade científica, de que o clima global tem sofrido alterações motivadas por essas atividades (Houghton et al. 2001, Levitus et al. 2001, Zwiers and Weaver, 2000), e que estão bem expressas na Contribuição do Grupo de Trabalho I ao Quarto Relatório do Painel Intergovernamental de Mudanças Climáticas (IPCC, 2007). É fato, porém, que existem ainda diversas dificuldades na quantificação da mudança no clima, visto que o sistema climático inclui um grande número de interações e limiares muito complexos (Alley et al. 2003).

Nesse contexto, os aerossóis atmosféricos respondem como uma das maiores fontes de incerteza na investigação dos cenários de mudança climática (Forest et al. 2002). Isto é particularmente verdadeiro, considerando que, como parte da cadeia de feedbacks envolvendo as nuvens, mudanças em grande escala na concentração e composição dos aerossóis podem levar a modificações gerais nas propriedades ópticas das nuvens e nos processos de formação de precipitação (Ramanathan et al. 2001, Kaufman et al. 2002). Relativamente aos demais componentes do sistema climático relevantes para as mudanças em curso no clima, admite-se que a margem de erro associada às estimativas nas contribuições dos aerossóis ainda é elevada, particularmente no que diz respeito ao chamado "efeito indireto", ou seja, alterações em propriedades de nuvens induzidas por partículas de aerossóis. Tal "efeito indireto" inclui tanto a influência sobre as propriedades ópticas de nuvens individuais, quanto sobre a duração do seu ciclo de vida, com impactos sobre a nebulosidade total média no planeta. Estimativas diversas apontam que o aumento na concentração de aerossóis nas colunas atmosféricas associado às atividades humanas, pode responder por um aumento de até $5 \%$ na nebulosidade (Kaufmann e Koren, 2006; Breón, 2006) e até $6 \%$ no albedo do campo de nuvens (Wielicki et al. 2005), o que incorpora o aumento da refletividade em nuvens individuais, associado ao número maior de gotículas (que servem como centros espalhadores de radiação solar) formado em massas de ar com maiores concentrações de núcleos de condensação.

O nível de compreensão científico acerca da influência dos aerossóis no clima, apesar de ter avançado significativamente nos últimos anos graças a uma atuação intensa de amplos setores da comunidade de ciências atmosféricas, ainda é relativamente baixo, especialmente quando comparado ao grau de compreensão do papel dos gases de efeito estufa (GEEs). De fato, segundo o IPCC (2007), o forçante radiativo atribuído aos GEEs é de aquecimento. Para o dióxido de carbono atribui-se um valor de forçante radiativa de $1,66 \mathrm{~W} \cdot \mathrm{m}^{-2} \pm 0,17 \mathrm{~W} \cdot \mathrm{m}^{-2}(1,49$ a $1,83 \mathrm{~W} \cdot \mathrm{m}^{-2}$ ). Enquanto isso, ao efeito indireto dos aerossóis é atribuído um valor de $-0,70 \mathrm{~W} . \mathrm{m}^{-2}$, mas com um intervalo de confiança $\left(-1,80\right.$ a $\left.-0,30 \mathrm{~W} . \mathrm{m}^{-2}\right)$ muito maior. Esta grande incerteza está ligada a um bom conhecimento qualitativo e a um baixo conhecimento quantitativo da contribuição antropogênica via efeito indireto (Baker e Peter 2008). Isto implica na necessidade de novos programas observacionais e esforços de modelagem.

As nuvens convectivas tropicais são um dos componentes mais importantes do sistema climático global, exercendo um papel crucial no balanço radiativo e no transporte de energia em escala planetária. É possível que alterações em sua microestrutura (das quais as provocadas por mudanças no campo dos aerossóis é uma das possibilidades) tenham impacto significativo em circulações atmosféricas de maior escala. Um incremento no número de aerossóis pode implicar em um aumento do albedo de nuvens individuais, na fração de cobertura de nuvens, na quantidade de água líquida disponível para processos de solidificação em altos níveis, em função da redução na eficiência de produção de precipitação na fase quente via colisão-coalescência (Lohmann e Feichter, 2005).

Neste contexto, tem sido feito um esforço da comunidade científica em realizar medidas de microfísica em nuvens tropicais. Entre as iniciativas realizadas com o objetivo de proporcionar conjuntos de dados microfísicos sobre os trópicos destacam-se o STEP (Stratosphere-Troposphere Exchange Project, Knollenberg et al. 1993), o CEPEX (Central Equatorial Pacific Experiment, CEPEX, Chen et al. 1997), o Experimento do Ceará em 1994 (Costa et al. 2000a), o LBA-TRMM (LargeScale Biosphere-Atmosphere Experiment in Amazonia - Tropical Rainfall Measuring Mission, Stith et al. 2002), o Experimento de Kwajalein (KWAJEX, Stith et al. 2002), e o LBA-SMOCCEMfiN! (Large-Scale Biosphere-Atmosphere Experiment in Amazonia - Smoke Aerosols, Clouds, Rainfall and Climate - Experimento de Microfísica de Nuvens, Andreae at al. 2004).

Sobre algumas regiões tropicais, como a Amazônia, a queima de biomassa é uma fonte significativa de aerossóis que servem como núcleos de condensação de nuvens (CCN), como apontado por Kaufman et al. 1998, Artaxo et al. 1998 e Artaxo et al. 2002. Mudanças na microfísica associadas com aerossóis de fumaça têm sido demonstradas por estudos de modelagem (Roberts et al. 2003), estimativas de satélite (e.g. Rosenfeld 1999 e Sherwood 2002) e medidas in situ (Andreae et al. 2004, Freud et al. 2008). Os resultados, de maneira geral, concordam que há uma influência significativa do aumento das concentrações de $\mathrm{CCN}$ devido às queimadas sobre as propriedades micro e macrofísicas das nuvens da região.

Nesse contexto, os modelos de nuvens, ao complementarem informações obtidas em campo, assumem um 
papel importante no intuito de reduzir incertezas. Há diversos fatores, que dificilmente podem ser investigados e quantificados apenas a partir de medidas experimentais, de tal forma que estudos observacionais podem ser complementados com o uso de modelos de diferentes graus de complexidade. A abordagem, neste casos, vai desde modelos de parcela simples (e.g. Nenes et al. 2001, 2002; Costa e Sherwood 2005) até modelos de nuvens mais complexos (e.g. Costa et al. $2001 \mathrm{a}$, b; Yin et al. 2000, 2002, etc.) e mesmo modelos globais com (Grabowski 2003) ou sem (Rotstayn e Lohmann 2002, Chuang et al. 2002 etc.) uma representação explícita das nuvens convectivas (a chamada "superparametrização").

Neste artigo, pretendemos abordar a questão dos aerossóis e da microfísica de nuvens com destaque para dados coletados em diversas campanhas do LBA (Large-Scale BiosphereAtmosphere Experiment in Amazonia) e em simulações para a Amazônia, discutindo os resultados científicos desse programa para um melhor entendimento científico do tema. Enfatizaremos, neste momento, a microfísica na fase quente, deixando a modelagem da fase de gelo para outra oportunidade.

\section{AEROSSÓIS}

As concentrações de partículas de aerossóis na bacia amazônica variam principalmente em função da atividade de queimadas, que tipicamente ocorrem na região da fronteira agrícola durante os meses de agosto-novembro (ainda que com pequenas diferenças regionais quanto à época em que as queimadas ocorrem). Durante a estação chuvosa, as concentrações de material particulado raramente ultrapassam
$10 \mu \mathrm{g} / \mathrm{m}^{3}$. Estes baixos valores são decorrentes de dois fatores: 1) ausência quase total de queimadas, limitando assim o montante de aerossóis na atmosfera às emissões biogênicas e ao transporte de longa distância - que inclui sal marinho e poeira do Saara; 2) constante remoção úmida (wash-out) dos aerossóis devido à intensa precipitação, típica da estação. Estes valores são observados tanto em áreas remotas (Pauliquevis et al., 2007; Artaxo et al., 1988, 1990, 2002) como também em áreas impactadas pelas plumas de queimadas (Artaxo et al., 2002). Em contrapartida, na estação seca, as diferenças regionais se ampliam significativamente. Pauliquevis et al. (2007) reportaram medidas contínuas de concentração de material particulado (MP) em Balbina, uma área remota localizada cerca de $150 \mathrm{~km}$ ao norte de Manaus e livre de emissões antrópicas. A Figura 1 mostra a série temporal de concentração de MP entre outubro de 1998 até setembro de 2004. Nota-se que nos semestres pares ocorre um aumento da concentração total de MP, exclusivamente devido a um incremento significativo da concentração de MP dos aerossóis da moda fina (diâmetro < $2,5 \mu \mathrm{m}$ ). Os autores identificaram, por análise de componentes principais absoluta, que este aumento é devido ao transporte de larga-escala de aerossóis de queimadas provenientes de outras regiões da Amazônia. Por outro lado, o particulado grosso $\left(2,5 \mu \mathrm{m}<\mathrm{d}_{\mathrm{p}}<10 \mu \mathrm{m}\right)$, mais associado a emissões locais, biogênicas, permanece com amplitude constante ao longo do período amostrado, o que indica a atuação de uma fonte de partículas com comportamento razoavelmente constante ao longo do ano. Este resultado é coerente com os de Decesari et al. (2006), o qual estimou que no início do período chuvoso a concentração total de carbono no domínio submicrométrico

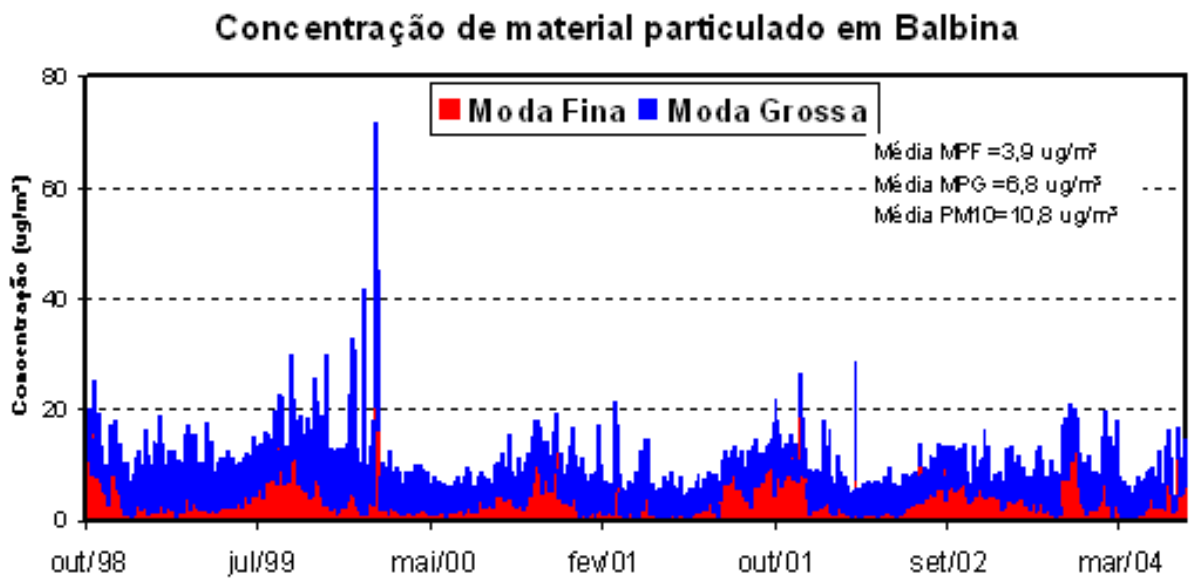

Figura 1 - Série temporal da concentração de material particulado medida em Balbina com amostradores AFG, no período de outubro de 1998 a setembro de 2004. MPF, MPG e PM10 representam, respectivamente, massa do particulado fino, massa do particulado grosso e massa do particulado inalável $\left(\mathrm{d}_{\mathrm{p}}<10 \mu \mathrm{m}\right)$. 
diminui cerca de 20 vezes, enquanto o particulado grosso mantém concentrações aproximadamente constantes.

O cenário é completamente diferente em Rondônia, estado fortemente afetado por queimadas. Durante o experimento LBA/SMOCC, as concentrações de material particulado atingiram patamar da ordem de $200 \mu \mathrm{g} / \mathrm{m}^{3}$, e constantemente ultrapassaram $100 \mu \mathrm{g} / \mathrm{m}^{3}$ (Artaxo et al. 2002; Fuzzi et al., 2007). A Figura 2 mostra medidas em tempo real realizadas durante o experimento, no período setembro-novembro de 2002, onde pode-se observar as altas concentrações atingidas. Em termos de comparação, o padrão brasileiro de qualidade do ar (Resolução
CONAMA $n^{\circ} 03$ de 28/06/90) indica que a concentração de MP inalável (PM10) não deve ultrapassar o valor de $150 \mu \mathrm{g} / \mathrm{m}^{3}$ na média de $24 \mathrm{~h}$ mais que uma vez por ano, e a média aritmética anual não deve ultrapassar $50 \mu \mathrm{g} / \mathrm{m}^{3}$.

Uma observação mais detalhada da Figura 2 mostra que o impacto das emissões de queimadas na estação seca não foi o mesmo durante todo o período de amostragem. Pode-se notar que o período entre 12 de setembro e 8 de outubro, foi o de maior impacto de emissões de queimadas (concentrações entre 13 e $200 \mu \mathrm{g} / \mathrm{m}^{3}$ ), com uma pequena interrupção entre 28 e 30 de setembro, devido à ocorrência de precipitação. A partir

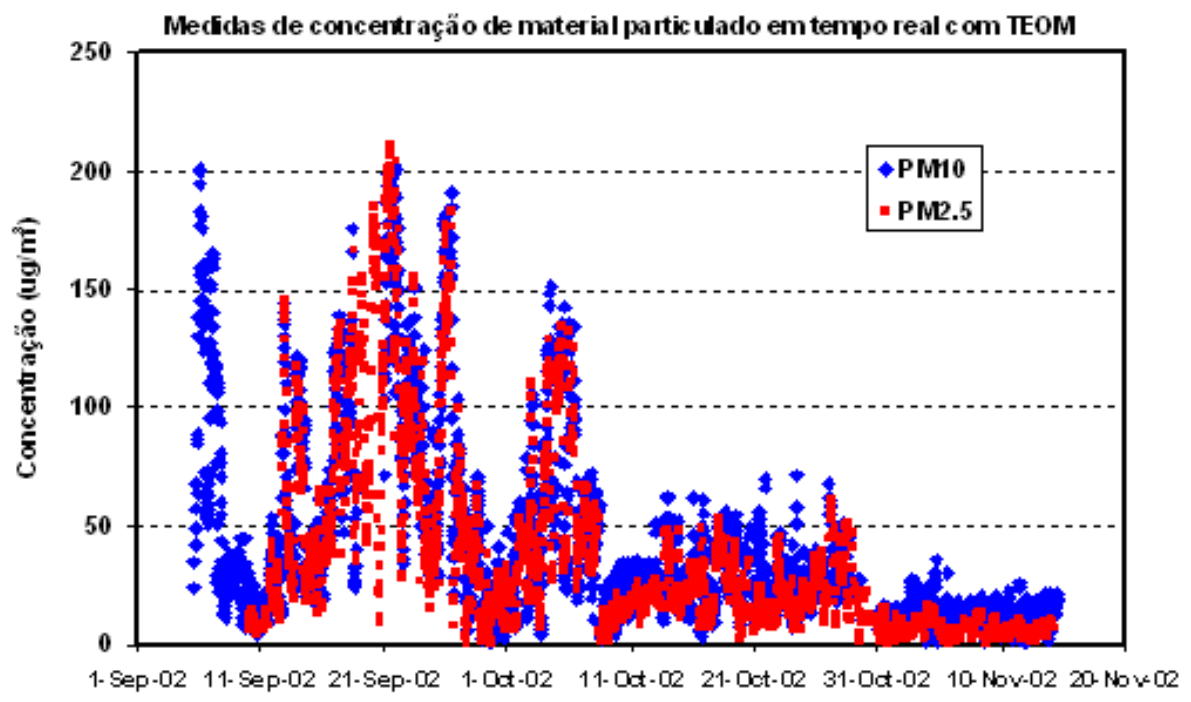

Figura 2 - Medidas de concentração de material particulado em tempo real, realizadas com um TEOM, para moda fina (PM2.5, $\mathrm{d}_{\mathrm{p}}<2.5$ um) e moda grossa $\left(\mathrm{PM} 10, \mathrm{~d}_{\mathrm{p}}<10 \mu \mathrm{m}\right)$. As medidas foram feitas em solo durante o experimento SMOCC, em Rondônia, no período da estação seca.

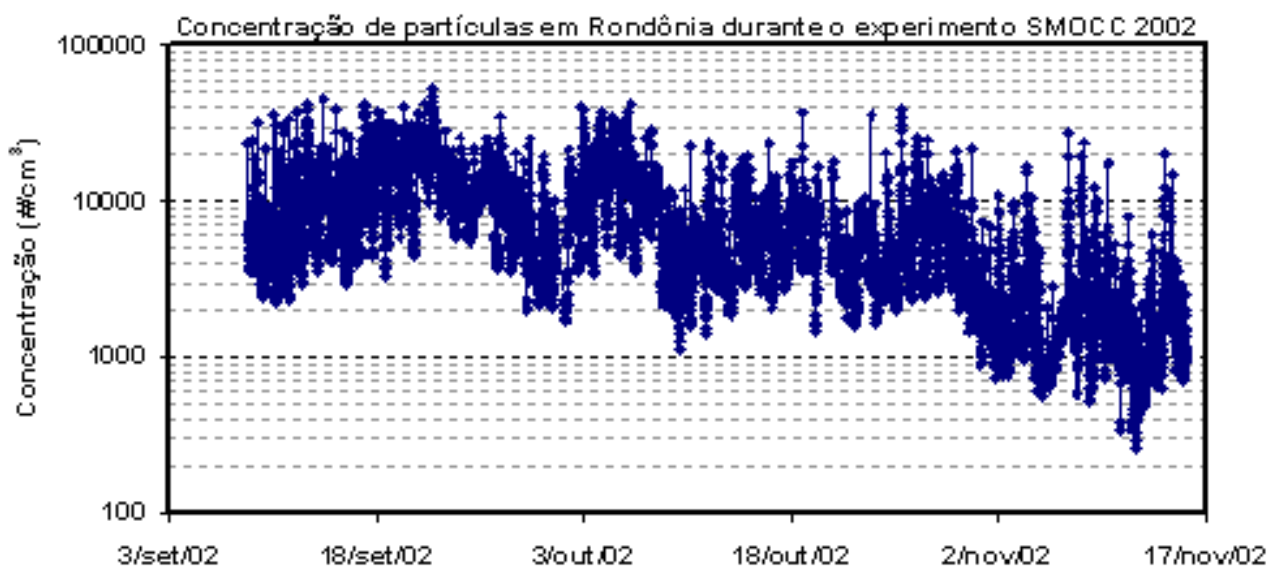

Figura 3 - Medidas de concentração de partículas coletadas durante o experimento SMOCC em Rondônia. A concentração de partículas variou em até 2 ordens de grandeza, em função do impacto de emissões de queimadas. 
de 09 de outubro a concentração de material particulado caiu significativamente (concentrações entre 4 e $60 \mu \mathrm{g} / \mathrm{m}^{3}$ ), sofrendo um novo decréscimo importante a partir de 31 de outubro (concentrações da ordem entre 3 e $9 \mu \mathrm{g} / \mathrm{m}^{3}$ ), quando a transição para a estação chuvosa dificultou a atividade de queimadas em maior escala.

A concentração (numérica) de partículas nestas duas regiões bastante representativas de níveis muito diferentes de influência da ocupação humana, também é muito diferente. Para Balbina, o valor médio da estação chuvosa é de $590 \pm$ $440 \mathrm{~cm}^{-3}$. Para Rondônia, mesmo os valores observados em novembro de 2002, na transição entre as estações seca e chuvosa, atingi-se patamares mais altos, com valor médio de $2100 \pm$ $2000 \mathrm{~cm}^{-3}$. Isto mostra, que áreas como Rondônia já sofrem o impacto de outras fontes de poluição que não as originadas em queimadas, o que explica estes valores de background mais altos mesmo neste período de transição, que já apresentava intenso regime de chuvas. De fato, a região tem a presença de

MOUDI CLAIPE 98 - Babina 30-31/ma / 1998

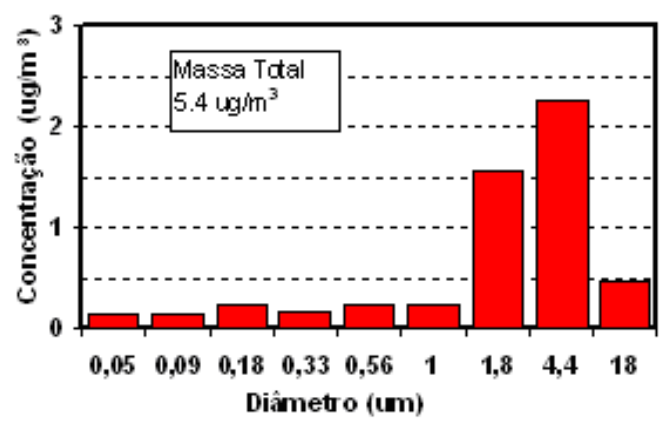

(a)

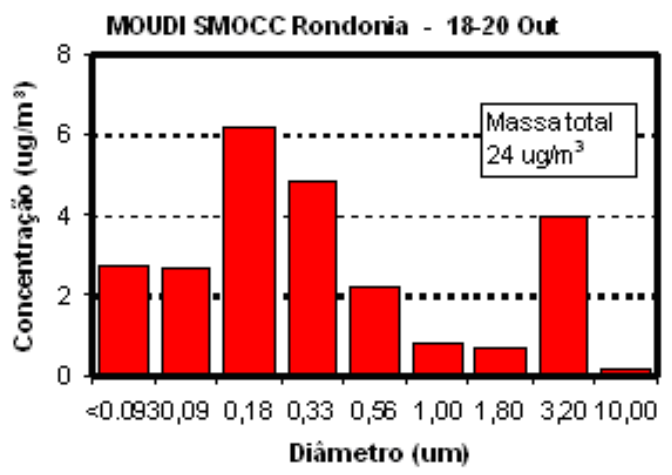

(c) várias carvoarias, que são uma fonte potencial para justificar esses patamares mínimos mais elevados do que os observados em regiões remotas.

Já nos períodos de maior impacto por queimadas (meses de setembro e outubro) a concentração de partículas atinge níveis muito altos, conforme pode ser observado na Figura 3, onde é apresentada a série temporal de concentração de partículas. Valores da ordem de $10.000 \mathrm{~cm}^{-3}$ foram comumente alcançados em setembro, atingindo valor máximo de até $40.000 \mathrm{~cm}^{-3}$.

Em termos de microfísica de nuvens, os parâmetros físicos mais importantes dos aerossóis atmosféricos são a concentração total e a distribuição de tamanho das partículas. Isso se deve ao fato da relação direta que há entre o aumento da concentração de partículas e a concentração de gotas dentro da nuvem. Assim, apesar da relação não ser diretamente proporcional ${ }^{(1)}$, um aumento significativo na concentração total de partículas implica em um também significativo aumento na concentração e uma redução no diâmetro médio de gotas de nuvens, com implicações

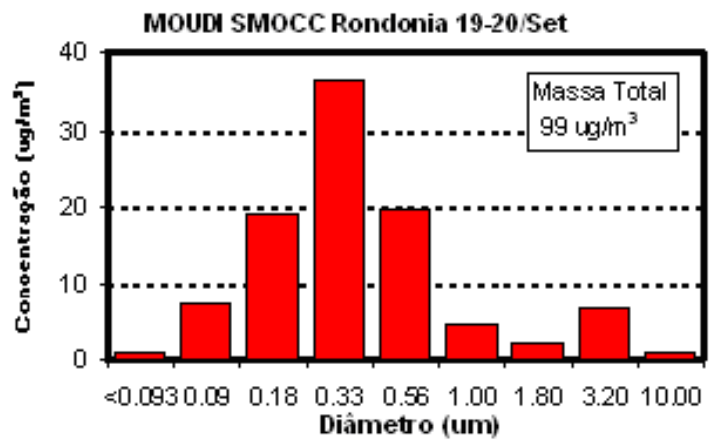

(b)

MOUDI SMOCC Rondonia - 6-10 Ilov

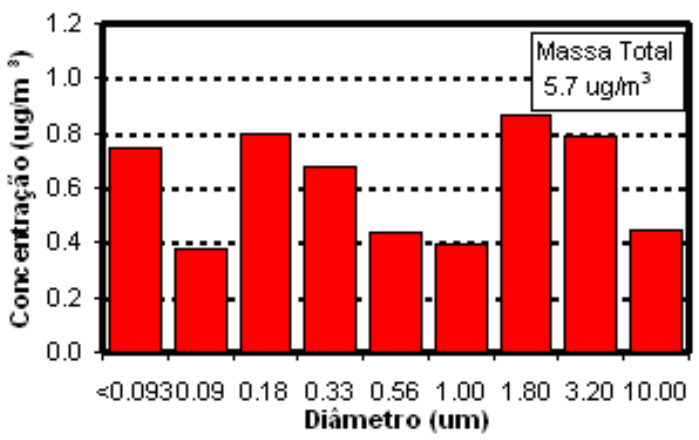

(d)

Figura 4 -Medidas de distribuição de tamanho obtidas com impactador em cascata (MOUDI). A figura (a) refere-se à Balbina, durante a estação úmida, enquanto as figuras (b), (c) e (d) referem-se aos três períodos distinguíveis de concentração de aerossóis durante o experimento LBA/SMOCC. Note as diferentes escalas verticais. É possível observar como há uma redução da concentração de MP em diâmetros menores conforme as concentrações totais de MP são menores, uma conseqüência do fato de partículas menores que $1 \mu \mathrm{m}$ predominarem nas emissões de queimadas.

\footnotetext{
${ }^{1}$ Um aumento nas concentrações de CCN implica uma redução na supersaturação máxima atingida dentro da nuvem, devido a maior competição entre as gotas por vapor de água. Dessa forma, aumenta o diâmetro de ativação mínimo (seco) dos CCN, o que reduz a proporção da população total de CCN que será ativada, a comumente denominada razão $\mathrm{CCN} / \mathrm{CN}$ (CN é a concentração total de partículas).
} 
importantes no ciclo de vida da nuvem posteriormente à fase de nucleação e crescimento por difusão de vapor.

Adistribuição de tamanho também é um fator fundamental na determinação do número de gotas ativadas dentro de uma parcela de ar ascendente, e que atinja um determinado valor máximo de supersaturação. A Figura 4 mostra medidas de concentração de material particulado em função do tamanho coletadas em Balbina e Rondônia, utilizando um impactador em cascata (MOUDI). No caso de Rondônia mostra-se uma amostra representativa de cada um dos três períodos distintos, observada durante o experimento LBA/SMOCC com relação à concentração de MP. No caso de Balbina, nota-se que há uma concentração maior do MP na faixa de tamanho acima de $1 \mu \mathrm{m}$. Em Rondônia, por outro lado, nota-se que a maior parte do MP encontra-se abaixo de $1 \mu \mathrm{m}$, um efeito devido às emissões de queimada que ocorrem nesta faixa de tamanho. Conforme a concentração de MP foi progressivamente sendo reduzida (o que ocorreu ao longo do experimento), houve uma redução deste

Tabela 1 - Valores médios de C and k obtidos durante o experimento LBA-SMOCC-EMfiN! para os diferentes regimes microfísicos. Para o regime "oceano verde" foram utilizados dados do experimento CLAIRE 98.

\begin{tabular}{|c|c|c|c|c|}
\hline \multicolumn{2}{|l|}{ Regime } & \multicolumn{2}{|c|}{$C$} & $\boldsymbol{k}$ \\
\hline Oceano Azul & Vôo & $20021018-1$ & 472 & 0.85 \\
\hline Oceano Verde & CLAIRE 98 & & 473 & 1.04 \\
\hline \multirow{6}{*}{ Poluído } & \multirow{5}{*}{ Vôos } & $20020921-3$ & 4873 & 1.35 \\
\hline & & $20020921-4$ & 5317 & 1.21 \\
\hline & & 20020923-1 & 5244 & 1.53 \\
\hline & & 20020926-1 & 5060 & 1.50 \\
\hline & & $20020927-1$ & 5208 & 1.56 \\
\hline & Média & & 5140 & 1.43 \\
\hline \multirow{6}{*}{ Transição } & \multirow{5}{*}{ Vôos } & $20021011-1$ & 2093 & 0.77 \\
\hline & & 20021011-2 & 2565 & 1.14 \\
\hline & & $20021012-1$ & 1974 & 0.87 \\
\hline & & 20021013-1 & 2096 & 0.70 \\
\hline & & 20021014-1 & 4510 & 1.41 \\
\hline & Média & & 2648 & 0.98 \\
\hline
\end{tabular}

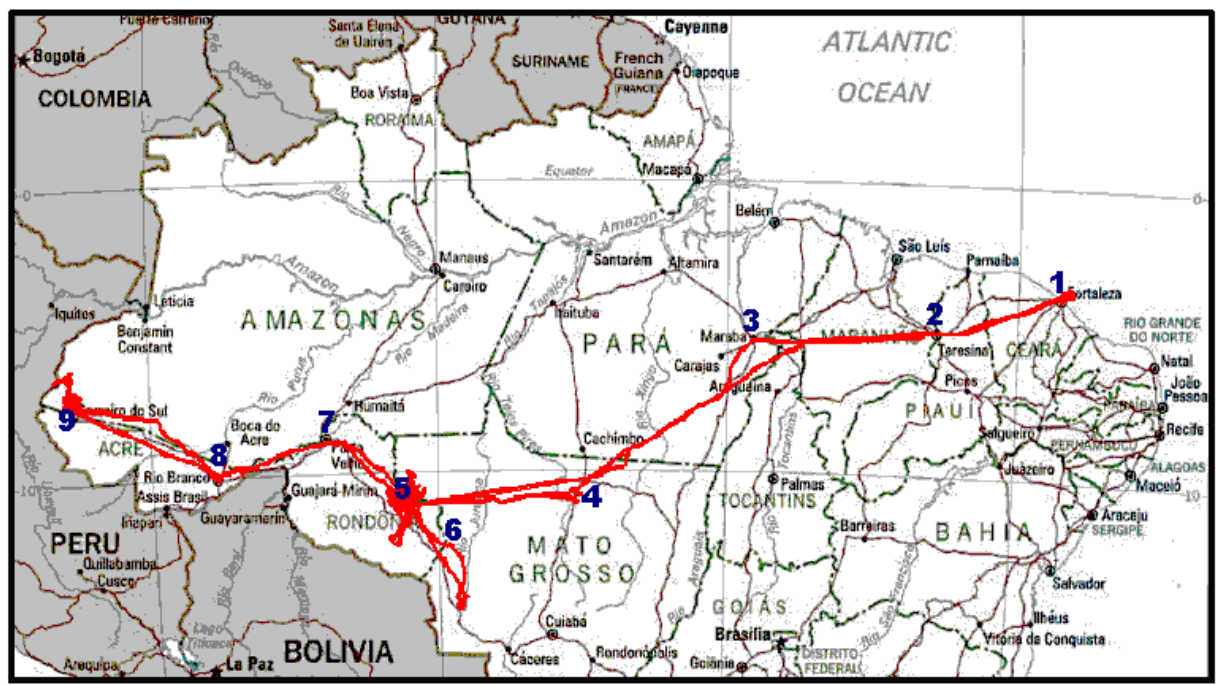

Figura 5 - Trajetórias da aeronave para os 32 vôos do LBA-SMOCC-EMfiN!, entre 21 de Setembro e 18 de Outubro. Algumas cidades são indicadas por números: 1. Fortaleza, 2. Teresina, 3. Marabá, 4. Alta Floresta, 5. Ji-Paraná, 6. Porto Velho, 7. Vilhena, 8. Rio Branco, 9. Cruzeiro do Sul. A variedade de ambientes investigados durante a campanha permitiu a caracterização de diferentes regimes microfísicos: marítimo, costeiro, continental limpo ("oceano verde"), poluído e de transição. 
efeito. No mês de novembro de 2002, quando já se configurava um regime de chuvas mais rigoroso e a concentração total de MP atingiu níveis similares aos observados em Balbina, ainda assim não se observou um padrão similar em Rondônia àqueles observados em regiões remotas como Balbina. De fato, apesar da concentração de MP ser similar, ainda há grande contribuição de partículas de tamanhos pequenos (vide Figura 4d) que contribuem pouco para a concentração em massa, mas que contribuem significativamente para a concentração numérica de partículas.

Durante o mesmo experimento, medidas de $\mathrm{CCN}$ a bordo do ALPA (Avião-Laboratório para Pesquisas Atmosféricas da Universidade Estadual do Ceará, cuja instrumentação é apresentada no apêndice A) foram realizadas para supersaturações variando tipicamente de $0,2 \%$ a $1,0 \%$, sobre diferentes regiões do Brasil, como indicado na Figura 5.

Equações do tipo $\mathrm{N}=\mathrm{C} \cdot \mathrm{S}^{\mathrm{k}}$ foram usadas para descrever a concentração total de $\mathrm{CCN}$ ativados como função da supersaturação (N indicando a concentração total de CCN ativados, $\mathrm{S}$ a supersaturação e $\mathrm{C}$ e k coeficientes ajustáveis). Pequenos valores de $\mathrm{C}$ (constante que corresponde a concentração de $\mathrm{CCN}$ a $\mathrm{S}=1,0 \%$ ) são tipicamente encontrados em massas de ar marítimas, ao passo que valores elevados de $\mathrm{C}$ são comumente associados a massas de ar poluídas. As observações de CCN realizadas foram ajustadas para leis de potência, sendo encontrados valores dos coeficientes ajustáveis típicos para cada regime. Os resultados são sintetizados na Tabela 1, onde são apresentados valores de $\mathrm{C}$ e $\mathrm{k}$ para os diversos vôos realizados, assim como valores médios para quatro regimes identificados. O regime poluído é caracterizado por concentrações de $\mathrm{CCN}$ muito altas (excedendo $5000 \mathrm{~cm}^{-3}, \mathrm{~S}$
$=1,0 \%$, assim como pela ativação de quantidades significativas de $\mathrm{CCN}$ em supersaturações mais altas, o que sugere a existência de um número substancial de partículas de aerossol pequenas (na faixa de $100 \mathrm{~nm}$ ). De maneira oposta, no regime de "oceano azul", pequenas concentrações de CCN são acompanhadas por um crescimento modesto no número de gotas ativadas à medida que a supersaturação cresce (a concentração de gotas ativadas aumenta cerca de 3 vezes no intervalo de supersaturação de $0,2 \%$ a $1,0 \%$, no caso do "oceano azul", ao passo que, para o regime poluído, esse aumento é de cerca de 7 vezes).

\section{MEDIDAS EXPERIMENTAIS EM MICROFÍSICA DE NUVENS}

As campanhas realizadas no Brasil demonstram a existência de uma grande variabilidade espacial no campo de aerossóis. No caso da Amazônia, destaca-se também a diferença radical entre as concentrações de gotículas encontradas durante os meses de Setembro e Outubro sobre os estados de Rondônia e Mato Grosso, e aquelas encontradas sobre o Oeste do estado do Amazonas, no mesmo período (Andreae et al. 2004), e sobre várias localidades, incluindo Rondônia, no período chuvoso (Stith et al. 2002, Santos et al. 2002), principalmente associadas a modificações nas propriedades microfísica induzidas pela grande variabilidade nas propriedades de aerossóis. Como exemplo, Santos et al. (2002) relatam concentrações de gotículas sempre menores do que $600 \mathrm{~cm}^{-3}$, e as concentrações típicas de hidrometeoros descritas por Stith et al. (2002) estiveram sempre limitadas a poucas centenas por centímetro cúbico. Por outro lado, concentrações de gotículas excedendo $3000 \mathrm{~cm}^{-3}$ foram

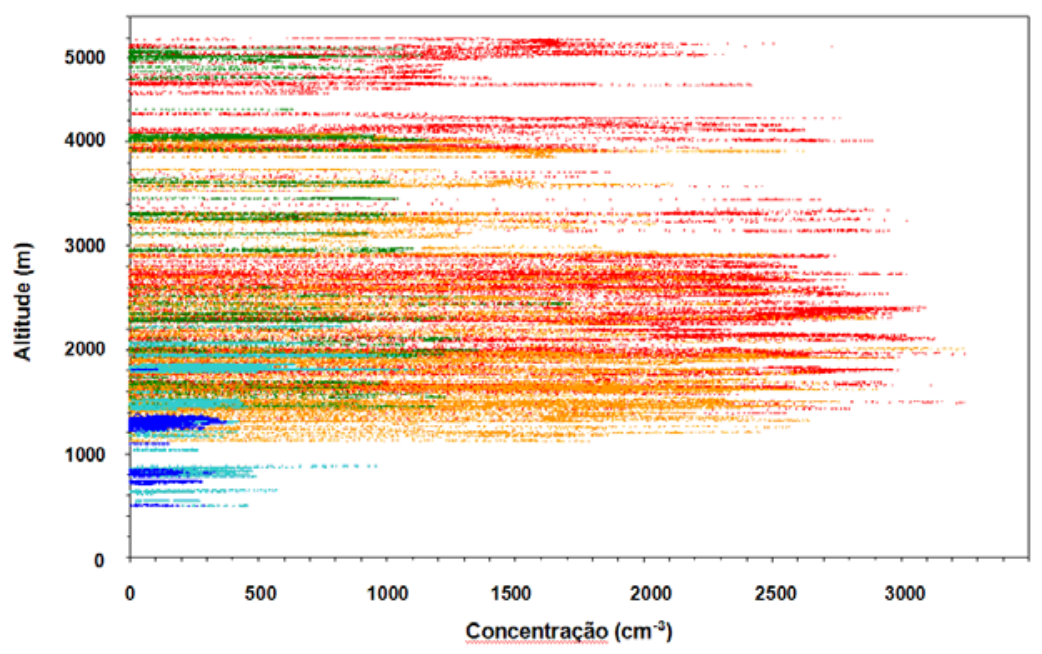

Figura 6 - Concentrações de gotículas medidas pela FSSP durante o LBA-SMOCC-EMfiN!: oceano (dados coletados em nuvens posicionadas sobre o mar, em azul), nuvens "costeiras" (dados coletados durante o vôo sobre o continente, próximo à costa, em ciano), "oceano verde" (em verde), regime poluído (em vermelho) e transição (em laranja). 
encontradas sistematicamente por Andreae et al. (2004) $)^{(2)}$ na mesma região durante o período seco, com forte influência de emissões de queimadas.

Uma significativa variedade de regimes microfísicos pôde ser observada durante a campanha do LBA-SMOCCEMfiN!, como pode ser observado pelo resultado de medidas in situ realizadas com a ALPA apresentados na Figura 5. As concentrações de gotículas medidas para esses regimes - marítimo (ou "oceano azul"), costeiro, continental limpo (ou "oceano verde"), poluído e de transição - são apresentadas na Figura 6. Fica evidente que, em ar poluído, as concentrações de gotículas são muito grandes, geralmente próximas a $3000 \mathrm{~cm}^{-3}$ (devido a possibilidade de erros de coincidência do instrumento estas concentrações podem estar subestimadas, conforme discutidos, por exemplo, em Brenguier 1989 e Cooper 1988). Tal quantidade de gotículas de nuvem sugere um significativo processo de inibição de desenvolvimento da precipitação na fase quente, uma vez que o vapor d'água disponível para condensação se distribui em um grande número de gotículas diminutas, com pequena chance de coagulação.

Diferenças significativas na forma do espectro de gotas de nuvens, também foram observadas com relação aos diferentes regimes microfísicos. As funções de distribuição de massa de hidrometeoros se mostraram mais estreitas em ambientes poluídos do que em ambientes limpos. A Figura 7 mostra exemplos de distribuições de massa de água líquida como função do diâmetro

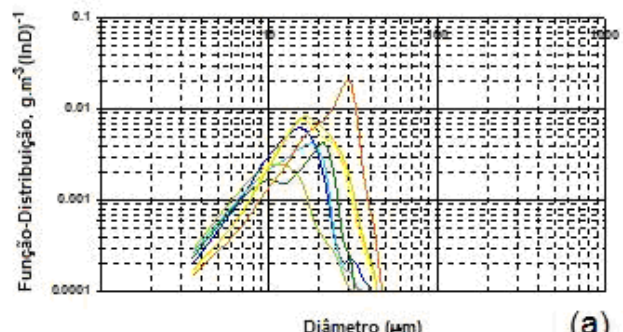

(a) das gotículas, baseados em dados de sondas espectrométricas embarcadas na aeronave. Tais funções-distribuição foram obtidas combinando os dados das sondas FSSP, 200X e 200Y, sendo que a estimativa do conteúdo de água líquida total obtida por intermédio das sondas mostra boa concordância com as medidas diretamente obtidas via sensor de fio quente (CSIRO-KING), conforme mostrado em Freud et al. (2008).

Os espectros são mostrados de tal maneira que seguem a evolução da função-distribuição de massa com a altura, permitindo verificar se há sinais de desenvolvimento de precipitação por mecanismos de colisão-coalescência na medida em que as parcelas são transportadas verticalmente no interior da nuvem. Vale ressaltar, que a classificação ora utilizada se diferencia ligeiramente daquela adotada por Andreae et al. (2004), visto que no presente artigo os pirocúmulos são tratados apenas como casos extremos na categoria poluída, já que seu comportamento segue as características gerais desse regime. A ênfase é dada aqui à distinção entre o regime de transição e o regime poluído (incluídos os pirocúmulos), em virtude da diferenciação entre estes regimes no que diz respeito à altitude de chuva quente, como será verificado posteriormente.

A Figura 7a corresponde às observações sobre o Oceano Atlântico, enquanto que a Figura $7 b$ exibe funções de distribuição de gotículas em nuvens sobre o continente, na região próxima a cidade de Fortaleza (CE). Espectros largos estão presentes, com um crescimento rápido do diâmetro modal, em ambos os casos,

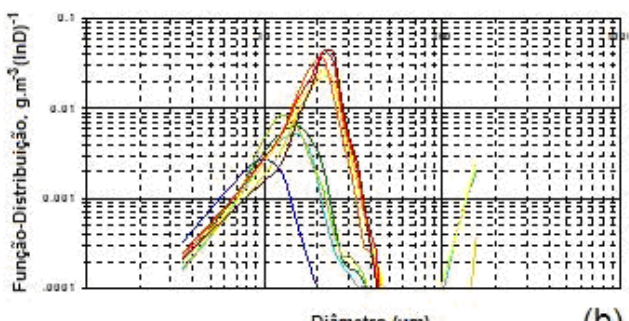

(b)

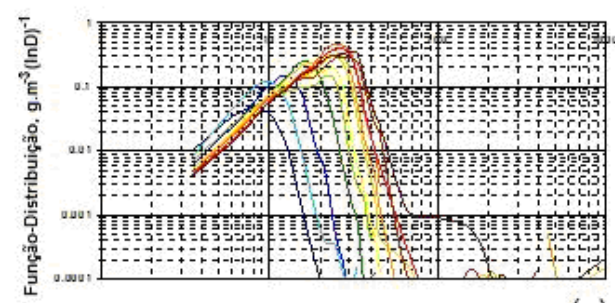

Diâmetro $(\mu \mathrm{m})$ (c)

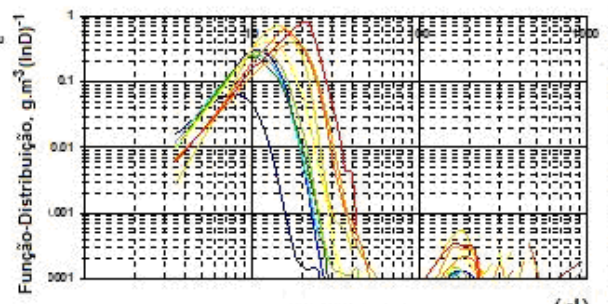

Diâmetro $(\mu \mathrm{m})$

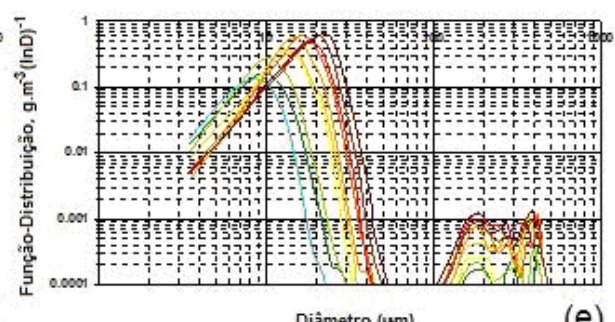

Diâmetro $(\mu \mathrm{m})$

Figura 7 - Distribuições em massa de hidrometeoros, em g.m $\mathrm{m}^{-3}(\operatorname{lnD})^{-1}$, para um vôo de cada um dos regimes microfísicos descritos: (a) Marítimo (medidas em altitudes médias de 678 m, 725 m, 943 m, 1060 m, 1182 m, $1345 \mathrm{~m}$ e $1710 \mathrm{~m}$ ), (b) Costeiro (579 m, $757 \mathrm{~m}, 1206 \mathrm{~m}, 1520 \mathrm{~m}, 1828 \mathrm{~m}$, 1911 m, 1946 m e 2131 m), (c) Continental limpo (1452 m, 1615 m, 1926 m, 2307 m, 2945 m, 3110 m, 3379 m, 3598 m, 3914 m, 4038 m, 4663 m e 4839 m), (d) Poluído (1620 m, 1926 m, 2011 m, 2442 m, 2650 m, 2825 m, 3232 m, 3933 m, 4019 m, 4906 m), (e) Transição (1432 m, 1629 m, 1892 m, 2181 m, 2393 m, 2580 m, 2923 m, 3143 m, 3630 m, 3931 m, 4040 m).

\footnotetext{
${ }^{2}$ Acredita-se que, especialmente no caso de pirocúmulos, as contagens de gotículas foram subestimadas por limitações do equipamento e que, na verdade, excedem esse patamar.
} 
o que concorda com observações de ecos de radar em nuvens com topos abaixo de $3000 \mathrm{~m}$ em Fortaleza (conforme apontado por Costa et al. 2002). Espectros observados sobre o "oceano verde" mostram um alargamento da função-distribuição similar às condições marítimas. Partículas gigantes, aparentemente não exercem nenhum papel significativo nessa massa de ar, uma vez que as partículas com dimensões de gotas de chuva crescem de maneira eficiente devido a condensação de vapor, efeito amplificado pela baixa concentração de partículas (vide crescimento rápido junto a "cauda" do espectro de gotículas (Figura 7c)). No ambiente poluído, a função de distribuição tipicamente apresenta duas modas (como na Figura 7d): o primeiro, composto de gotículas pequenas (raio modal abaixo de $10 \mu \mathrm{m}$ ); o segundo, de partículas grandes (raio próximo a $100 \mu \mathrm{m}$ ). Percebe-se que o modo de partículas pequenas não se alarga como no caso do "oceano verde", nem existe um crescimento significativo na massa do modo de partículas grandes com a altura. Uma possível explicação para isso é que, durante o processo de colisão/coalescência, uma grande diferença de tamanho entre as gotas coletora/coletada favorece que a gota menor siga o fluxo de ar ao redor de uma partícula maior em queda (um efeito de turbulência). Assim, a coleta dessas pequenas gotículas pelas gotas maiores não é significativa e o processo de formação da chuva quente não se desenvolve. Durante o período de transição, as concentrações de aerossol ainda são elevadas, mas inferiores àquelas encontradas durante o fim da estação seca, na qual se concentram as queimadas. Adicionalmente, há mais vapor d'água disponível em baixos níveis, devido a mudanças na circulação de grande escala sobre a região. Como conseqüência, a base das nuvens é rebaixada e gotas de chuva aparecem mais rapidamente, com capacidade de coletar gotículas ligeiramente maiores (comparadas àquelas encontradas no ambiente poluído), presentes graças à redução na concentração de CCN. É possível que, em certa medida, o processo de desenvolvimento de chuva quente esteja presente em tais circunstâncias, como sugerido pela Figura 7e.

A conseqüência das diferentes concentrações de gotículas, é que o processo de produção de chuva quente via colisãocoalescência é inteiramente distinto nos regimes descritos. Em ambientes limpos, o rápido alargamento do espectro associado às colisões deriva diretamente da nucleação e rápido crescimento por condensação de vapor de um pequeno número de gotículas e da abundância de vapor d'água disponível para o crescimento individual de cada hidrometeoro. Em contrapartida, em ambientes com maiores concentrações de aerossóis, a chuva quente é inibida e é possível que aerossóis gigantes possam ter uma influência significativa. Esse processo de inibição é sucessivamente agravado, quando se consideram nesta ordem, os regimes de transição, poluído e os pirocúmulos.

Tal processo pode ser quantificado pela altitude de chuva quente definida como a altura, na qual a distribuição de hidrometeoros atinge um valor mínimo que se atribui ao diâmetro modal em massa necessário para iniciar um rápido crescimento de gotas via colisão-coalescência. No presente trabalho, a mesma foi estimada através de uma interpolação linear (ou extrapolação, para os casos mais poluídos) da relação

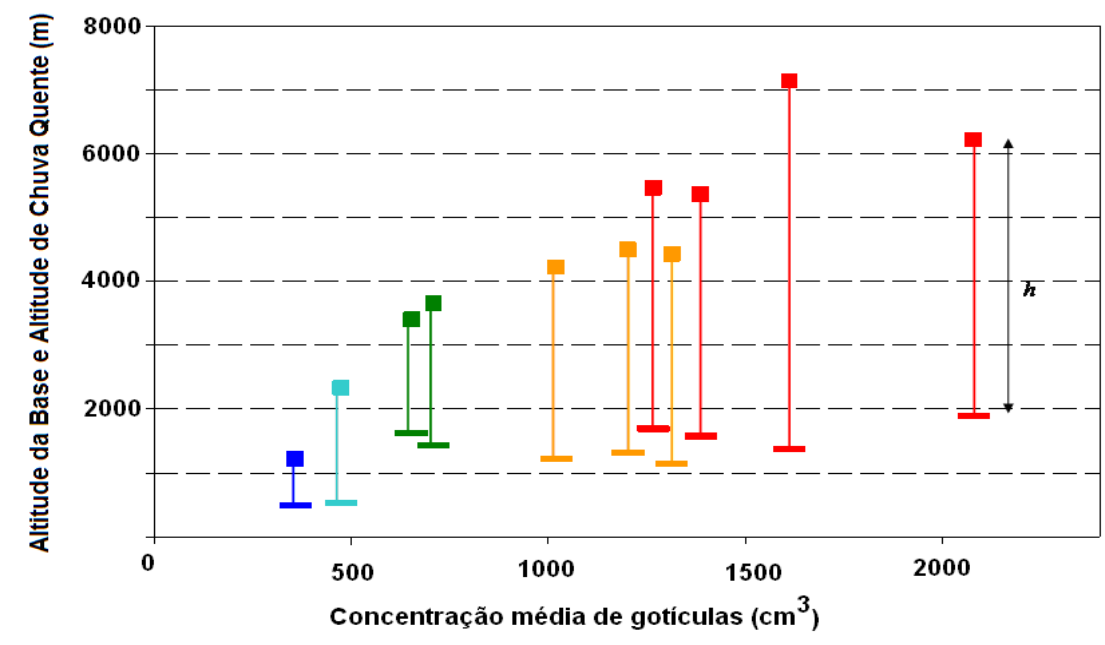

Figura 8 - Altitude de chuva quente e altitude da base da nuvem (em m) como função da concentração média de gotículas $\left(\mathrm{em} \mathrm{cm}^{-3}\right)$. Os vários regimes de microfísica de nuvens aparecem representados por cores diferentes: marítimo (azul), costeiro (ciano), "oceano verde" (verde), poluído (vermelho) e transição (laranja). A profundidade de chuva quente (h) é indicada pela distância vertical entre a base da nuvem e o nível de formação da chuva quente. 
observada, em cada vôo, entre altitude e diâmetro modal em massa. A altitude de chuva quente em diversos vôos é mostrada na Figura 8, juntamente com a altura típica da base das nuvens observadas em cada regime.

Definindo a altitude de chuva quente e a profundidade de chuva quente (altitude de chuva quente menos altura da base da nuvem), pelas variáveis $\zeta \mathrm{e} \mathrm{h}$, respectivamente, valores da ordem de $\zeta \approx 1200 \mathrm{~m}(\mathrm{~h} \approx 700 \mathrm{~m})$ sobre o oceano e $\zeta \approx 2300 \mathrm{~m}$ $(\mathrm{h} \approx 1800 \mathrm{~m})$ sobre o continente foram encontrados e concordam com observações de radar em Fortaleza, que mostram um desenvolvimento abundante de precipitação em nuvens com topos da ordem de (ou mesmo abaixo de) $3000 \mathrm{~m}$. Valores de $\zeta$ $\approx 3500 \mathrm{~m}(\mathrm{~h} \approx 2000 \mathrm{~m})$ para o "oceano verde" estão localizados bem abaixo do nível de congelamento, o que novamente é coerente com o desenvolvimento de chuva quente. Nuvens do regime de transição estão, aparentemente, numa situação fronteiriça, na medida em que a altitude de chuva quente está localizada próxima à isoterma de $0^{\circ} \mathrm{C}(\zeta \approx 4400 \mathrm{~m}, \mathrm{~h} \approx 3200$ $\mathrm{m})$. Por fim, no ambiente poluído, as gotículas crescem até diâmetro (modal, em massa) de apenas $\mathrm{DL}=18 \mu \mathrm{m}$ no nível de congelamento, bem abaixo do limiar aceito de $24 \mu \mathrm{m}$ (Andreae et al. 2002), e portanto longe do que se considera necessário para iniciar a precipitação. De acordo com a Figura 8 , um valor de $\zeta$ $\approx 5400-7100 \mathrm{~m}(\mathrm{~h} \approx 3800-5800 \mathrm{~m})$ é estimado para as nuvens poluídas. Nelas, o processo de desenvolvimento da precipitação na fase quente é inibido e o surgimento de partículas de gelo passa a ser crucial para a formação de chuva.

Tais resultados apresentam forte implicação em modelagem atmosférica. Em modelos de resolução mais grosseira, as parametrizações de convecção precisam incorporar o efeito das menores (maiores) concentrações de aerossóis na maior (menor) produção de precipitação na forma de chuva quente e na menor (maior) disponibilidade de água líquida para processos de solidificação com subseqüente liberação de calor latente reduzida (aumentada) em altos níveis. Tais fatores são importantes não só para a previsão quantitativa de chuva, como também têm implicações na circulação atmosférica de maior escala na presença de convecção. Por outro lado, alguns modelos de mesoescala utilizados operacionalmente em previsão de tempo se aproximam ou, até mesmo já utilizam uma resolução espacial fina o suficiente para resolver, ao menos parcialmente, os sistemas de nuvens, o que impõe a escolha apropriada de parâmetros microfísicos. Tanto em um caso como no outro, alterações naturais e antrópicas na microestrutura das nuvens, precisam ser levadas em conta em virtude da influência da microfísica sobre processos diversos como a interação das nuvens com a radiação, a produção de precipitação, o perfil de aquecimento e secagem convectivos, etc.

\section{MODELAGEM DA FASE QUENTE}

\subsection{Esquemas de Microfísica Detalhada}

Nos modelos de microfísica detalhada (e.g., Kogan 1991, Khain et al. 1999, Costa et al. 2000b, Lynn et al. 2005), como os hidrometeoros são classificados por tamanho, as fontes e sumidouros de cada categoria (ou "bin") estão ligados não só ao surgimento ou desaparecimento de hidrometeoros, mas também à mudança no tamanho destas partículas. Por exemplo, em um modelo de microfísica detalhada para a fase

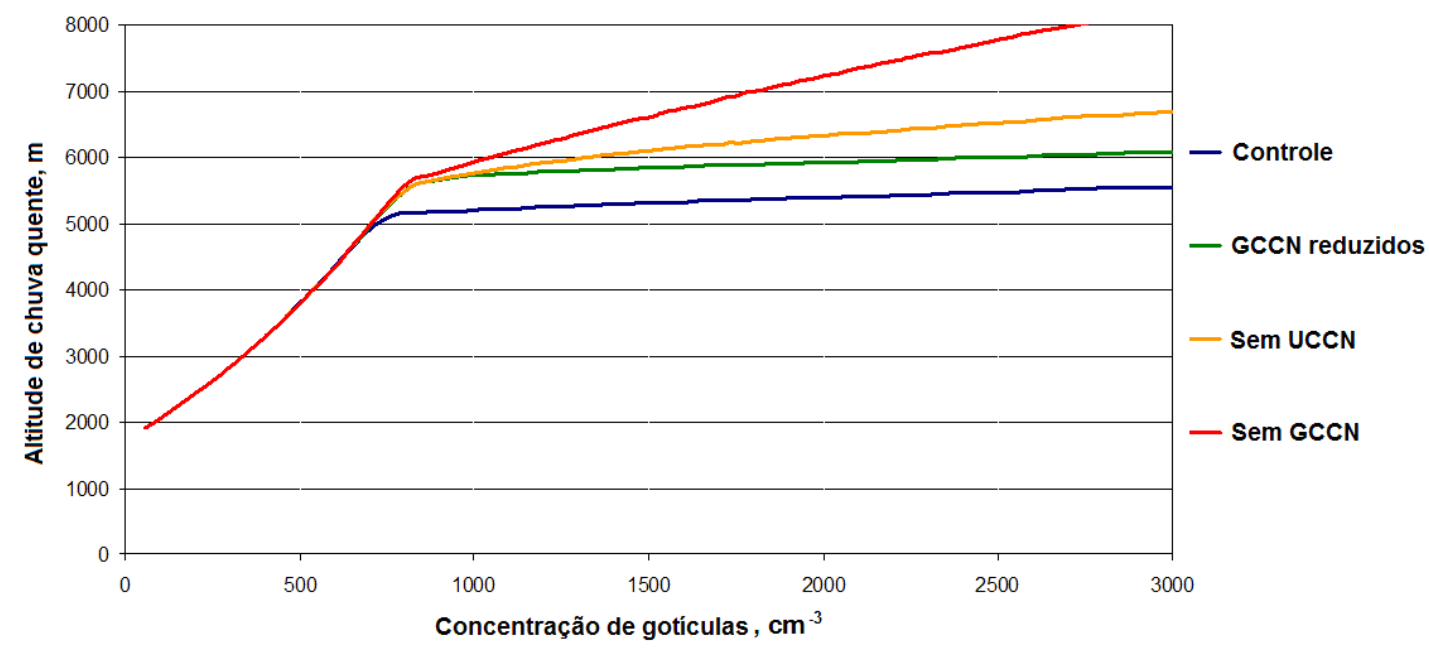

Figura 9 - Altitude de chuva quente simulada, como função da concentração de gotículas, para diferentes distribuições de CCN: controle, com concentrações reduzidas de GCCN e UCCN, sem UCCN e sem GCCN.

Adaptado de Costa e Sherwood (2005). 
líquida, a equação prognóstica para a função de distribuição (considerando um total de $\mathrm{M}$ categorias por tamanho) envolve termos de nucleação, condensação/evaporação, coalescência, ruptura colisional, que ocorre quando duas gotas, ao colidirem, produzem uma distribuição de fragmentos e de ruptura espontânea, que consiste na quebra de uma gota de grandes dimensões, hidrodinamicamente instável, gerando um conjunto de gotas menores. Matematicamente, isto é representado pela Equação 1:

$$
\begin{gathered}
\frac{\partial f_{m}}{\partial t}+V \cdot \nabla f_{m}=\left(\frac{\partial f_{m}}{\partial t}\right)_{n u c} \pm\left(\frac{\partial f_{m}}{\partial t}\right)_{c / e} \\
\pm\left(\frac{\partial f_{m}}{\partial t}\right)_{c o a} \pm\left(\frac{\partial f_{m}}{\partial t}\right)_{c b r k} \pm\left(\frac{\partial f_{m}}{\partial t}\right)_{s b r k}
\end{gathered}
$$

$\mathrm{Na}$ equação (1), $\mathrm{m}=1, \ldots, \mathrm{M}$ representa a $\mathrm{m}$-ésima categoria de tamanho e, portanto, o que temos na verdade é um conjunto de $\mathrm{M}$ equações a ser implementado no modelo.
A nucleação é uma fonte de gotas (e um sumidouro de CCNs). Tanto a condensação como a evaporação podem ser fontes ou sumidouros, a depender da classe de tamanho. Uma gota, ao crescer por condensação deve ser retirada de sua classe original $\mathrm{m} 1$ para uma outra classe de tamanho $\mathrm{m} 2>\mathrm{m} 1$. Daí, a condensação deve aparecer como fonte na equação de fm2 e sumidouro na equação de $f_{m l}$. Para a evaporação, aplica-se um raciocínio similar, considerando-se apenas que a gota diminui de tamanho.

No caso da coalescência, considera-se, por exemplo, uma gota pertencente à $\mathrm{m}_{1}$-ésima categoria interagindo com uma gota da $\mathrm{m}_{2}$-ésima categoria, produzindo uma gota da $\mathrm{m}_{3}$-ésima categoria, tal que a massa desta última é a soma das massas das gotas que lhe deram origem. Neste exemplo, o termo de coalescência surge como fonte na equação para $f_{m 3}$ e sumidouro nas equações de $f_{m 1}$ e $f_{m 2}$.

Seguindo a mesma linha de raciocínio, o termo de ruptura colisional referente à interação de gotas das categorias $\mathrm{m}_{1} \mathrm{e}$ $\mathrm{m}_{2}$, aparece como sumidouro nas equações destas classes de tamanho e como fonte nas equações das categorias que contêm
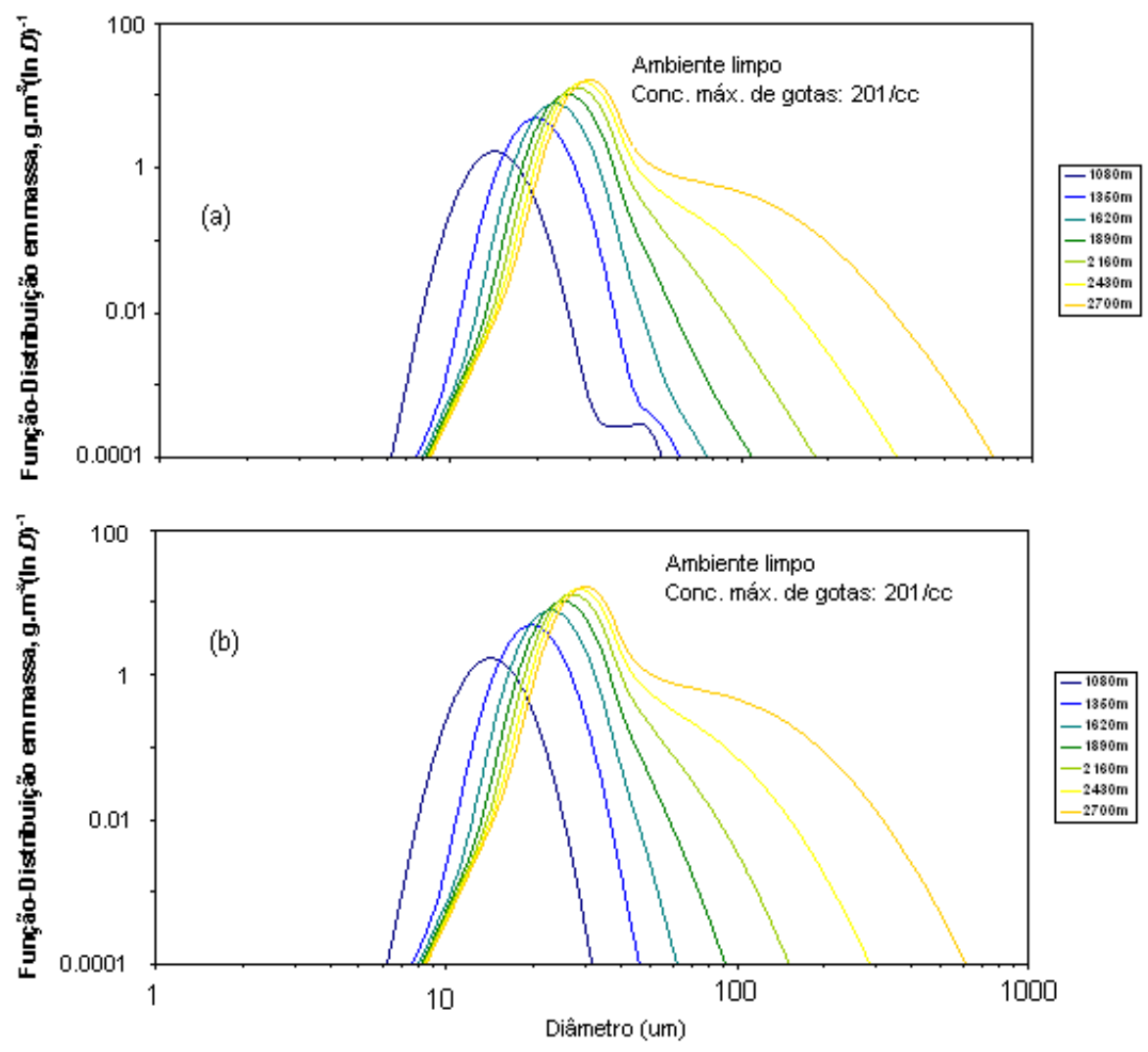

Figura 10 - Funções-distribuição em massa simuladas pelo modelo de parcela para ambiente limpo, (a) com e (b) sem GCCN. Curvas diferentes indicam a evolução temporal do espectro de gotículas (correspondendo às altitudes mostradas na legenda).

Adaptado de Costa e Sherwood (2005). 
os fragmentos. O mesmo se aplica à ruptura espontânea.

Estes esquemas conseguem prever a evolução do espectro, ou seja, da distribuição de hidrometeoros por tamanho. No entanto, como cada categoria requer uma equação prognóstica para ser resolvida, esta classe de esquemas costuma requerer muito tempo de computação, sendo raro o uso desse tipo de esquema em modelos de previsão.

Costa e Sherwood (2005) mostraram, através de um modelo simples de parcela, com microfísica detalhada, que aspectos fundamentais da elevada concentração de gotículas em ambientes poluídos (como o da Amazônia durante o período das queimadas) podem ser corretamente representados. Ademais, os autores apresentaram inferências acerca do papel exercido por uma variedade de fatores, em especial a presença de aerossóis gigantes, sua concentração e tamanho.

A Figura 9 mostra a altitude de chuva quente simulada com o modelo de parcela de Costa e Sherwood para quatro conjuntos de experimentos numéricos: controle (incluindo CCN gigantes ou GCCN), sem GCCN, com concentrações reduzidas GCCN e sem CCN ultra-gigantes (ou UCCN). Em concordância com estudos anteriores (e.g., Yin et al. 2000), os resultados sugerem que GCCN e UCCN são irrelevantes para o desenvolvimento da precipitação, quando a concentração de gotículas é inferior a 700-800 $\mathrm{cm}^{-3}$, mas acima dessa faixa de valores, o papel dos GCCN e UCCN em reduzir a altitude de chuva quente passa a ser significativa. Para ambientes muito poluídos com concentrações de gotículas da ordem de 2000 $\mathrm{cm}^{-3}$, a diferença na altitude de chuva quente entre a simulação de controle (isto é, com GCCN e UCCN) e a simulação sem GCCN é de cerca de $2 \mathrm{~km}$ para as condições iniciais e para a velocidade vertical utilizadas pelos autores. Os resultados do modelo sugerem que a minúscula população de partículas ultragigantes, também é importante e que sua ausência, na simulação sem UCCN, leva a um aumento de aproximadamente $1 \mathrm{~km}$ na altitude de chuva quente. Os resultados do experimento de sensibilidade com concentrações reduzidas de GCCN e UCCN sugerem que sua presença, mesmo em concentrações muito pequenas (relativamente à concentração total de $\mathrm{CCN}$ ), reduz a altitude de chuva quente em comparação com a simulação sem GCCN e UCCN.

Tais conclusões são corroboradas pela análise das distribuições de gotículas simuladas. Costa e Sherwood

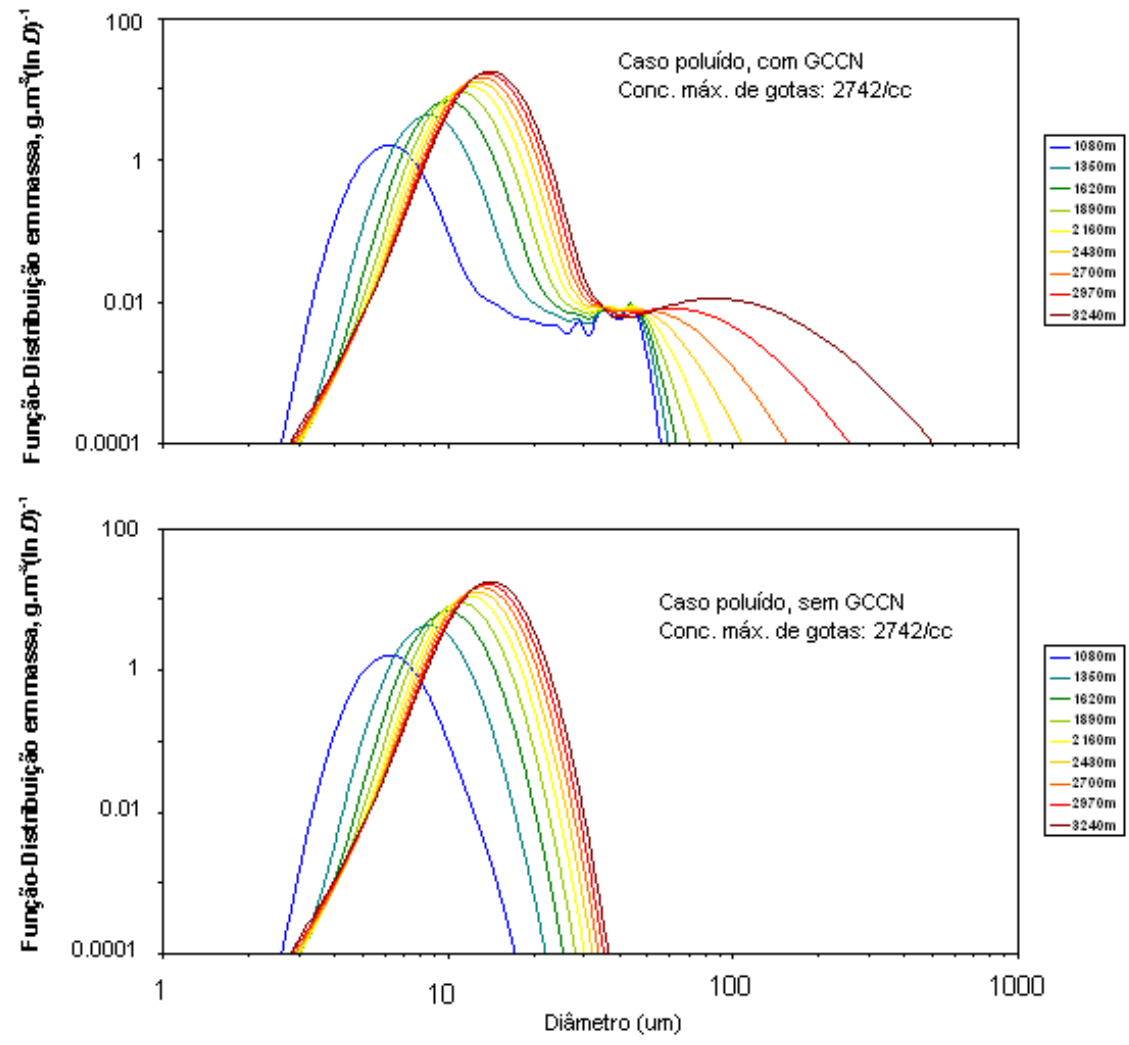

Figura 11 - Como na Figura anterior, para o caso poluído. 
(2005) encontraram que, no caso limpo, durante o estágio de crescimento condensacional, a massa adquirida pelas partículas menores é bastante significativa (uma vez que há poucas delas para competir pelo vapor d'água) e o diâmetro modal da funçãodistribuição em massa cresce rapidamente, processo que ocorre independente da presença ou não de GCCN, conforme ilustrado na Figura 10. Nela, espectros de gotas simulados pelo modelo de parcela são mostrados para diferentes altitudes, mostrando o alargamento do espectro para as simulações (a) de controle e (b) sem GCCN no caso limpo (concentrações máximas de aproximadamente $200 \mathrm{~cm}^{-3}$ ). Verifica-se que a presença dos GCCN é praticamente irrelevante, e que a "chuva quente" se desenvolve em ambos os casos.

O desenvolvimento deste processo é diferente em ambientes poluídos. Neste caso, gotículas nucleadas sobre aerossóis gigantes são capazes de ganhar massa através da coleta de algumas das partículas menores (pelo menos aquelas que não são diminutas, de modo a não seguirem o fluxo de ar ao redor da partícula coletora) e o crescimento das partículas maiores via coleta é mais rápido que o crescimento condensacional, devido ao grande número de partículas competindo pelo vapor de água que limita o segundo. Neste caso, conforme ilustrado na Figura 11 , há uma diferença significativa no comportamento de nuvens em ambientes poluídos (no caso da Figura, com concentrações máximas acima de $2700 \mathrm{~cm}^{-3}$ ) na presença (Figura 11a) e na ausência de GCCN (Figura 11b). Em oposição à simulação de controle, aqueles sem $\mathrm{CCN}$ não produzem nenhum alargamento perceptível do espectro de gotas.

A idéia de que gotículas maiores nucleadas sobre GCCN podem servir como embriões de precipitação não é nova (ver, por exemplo, Johnson 1982), mas ainda é objeto de debate se a presença de partículas gigantes de fumaça ou cinza na atmosfera poluída da Amazônia, durante o período das queimadas poderia ao menos mitigar a supressão do desenvolvimento de chuva quente associada com as altas concentrações totais de CCN. Os resultados mostrados sugerem que a presença de GCCN pode ser um dos fatores que atuam nas mudanças das propriedades das nuvens durante a transição do período seco para o período chuvoso. Ou seja, dependendo da concentração de GCCN no ambiente da nuvem, pode haver implicações significativas até mesmo para o desenvolvimento de precipitação na fase de gelo, uma vez que gotas grandes são candidatas a embriões de grandes cristais de gelo e partículas de saraiva, coletores eficientes de gotículas líquidas em nuvens profundas.

\subsection{Esquemas de Microfísica Totalizada}

Em contraste com os modelos de microfísica detalhada, as parametrizações de microfísica totalizada se caracterizam por utilizar como variáveis prognósticas, um número limitado de propriedades globais dos hidrometeoros. Em geral, estes são separados em classes como "conteúdo de água de nuvem" (gotículas menores do que um dado raio, cuja velocidade terminal pode ser considerada desprezível), "conteúdo de água de chuva" (gotas precipitantes) e diferentes classes de gelo, dependendo da complexidade do modelo (e.g., cristais, agregados, saraiva e granizo). Se somente uma variável prognóstica for utilizada (via de regra, a razão de mistura), o esquema é dito de "um momento" (e.g., Walko et al. 1995). Neste caso, se o usuário especificar a concentração de hidrometeoros para aquela classe, o modelo diagnosticará o diâmetro médio correspondente e vice-versa. Para o caso em que, além da razão de mistura, outra variável - em geral a concentração - é também prognosticada, deixando apenas o diâmetro médio a ser diagnosticado, o esquema é dito de "dois momentos" (Meyers et al. 1997). Limitando-se à fase líquida, a partição da água se dá somente nas categorias de vapor

Tabela 2 - Equações para as funções-distribuição exponencial, gama, lognormal e Weibull e expressões para seus respectivos diâmetros de escala. De Costa et al. (2000a).

\begin{tabular}{|c|c|c|}
\hline $\begin{array}{c}\text { Função- } \\
\text { Distribuição }\end{array}$ & Expressão Matemática & Diâmetro de Escala (Declividade) \\
\hline Exponencial & $N(D)=\frac{N_{t}}{D_{0}} \exp \left(-\frac{D}{D_{0}}\right)$ & $D_{0}=\left(\frac{q_{l}}{\pi \rho_{v} N_{t}}\right)^{1 / 3}$ \\
\hline Gama & $N(D)=\frac{N_{t}}{\Gamma(v)}\left(\frac{D}{D_{0}}\right)^{v-1} \frac{1}{D_{0}} \exp \left(-\frac{D}{D_{0}}\right)$ & $D_{0}=\left[6 \frac{\Gamma(v)}{\Gamma(v+3)} \frac{q_{l}}{\pi \rho_{w} N_{t}}\right]^{1 / 3}$ \\
\hline Lognormal & $N(D)=\frac{N_{t}}{\sqrt{2 \pi} \ln \sigma} \frac{1}{D} \exp \left\{-\frac{1}{2}\left[\frac{\ln \left(D / D_{0}\right)}{\ln \sigma}\right]^{2}\right\}$ & $D_{0}=\left\{6 \frac{q_{l}}{\pi \rho_{w} N_{t}} \exp \left[-4,5(n \sigma)^{2}\right]\right\}^{1 / 3}$ \\
\hline Weibull & $N(D)=N_{t} \mu\left(\frac{D}{D_{0}}\right)^{\mu-1} \frac{1}{D_{0}} \exp \left[-\left(\frac{D}{D_{0}}\right)^{\mu}\right]$ & $D_{0}=\left[\frac{6}{\Gamma(1+3 / \mu)} \frac{q_{l}}{\pi \rho_{w} N_{t}}\right]^{1 / 3}$ \\
\hline
\end{tabular}


d'água, água de nuvem e água de chuva, limitando o número de equações prognósticas a um total de três (um momento), cinco (dois momentos), o que é computacionalmente muito menos dispendioso do que as várias dezenas ou centenas de equações prognósticas dos esquemas detalhados.

Ao menos implicitamente, alguma função de distribuição de tamanho para os hidrometeoros em cada classe precisa ser sempre atribuída em esquemas de microfísica totalizada. Mesmo que não explicitamente, na maior parte dos casos, esquemas simplificados como as antigas parametrizações de Kessler, Berry, Berry-Reihardt (respectivamente Kessler, 1969; Berry, 1967; Berry e Reinhard, 1974 a, b) e outras se utilizaram de distribuições monodispersas (função delta) ou do tipo Marshall-Palmer (i.e, exponenciais). Mais recentemente, funções-distribuições que melhor representam espectros de hidrometeoros observados vêm sendo propostas
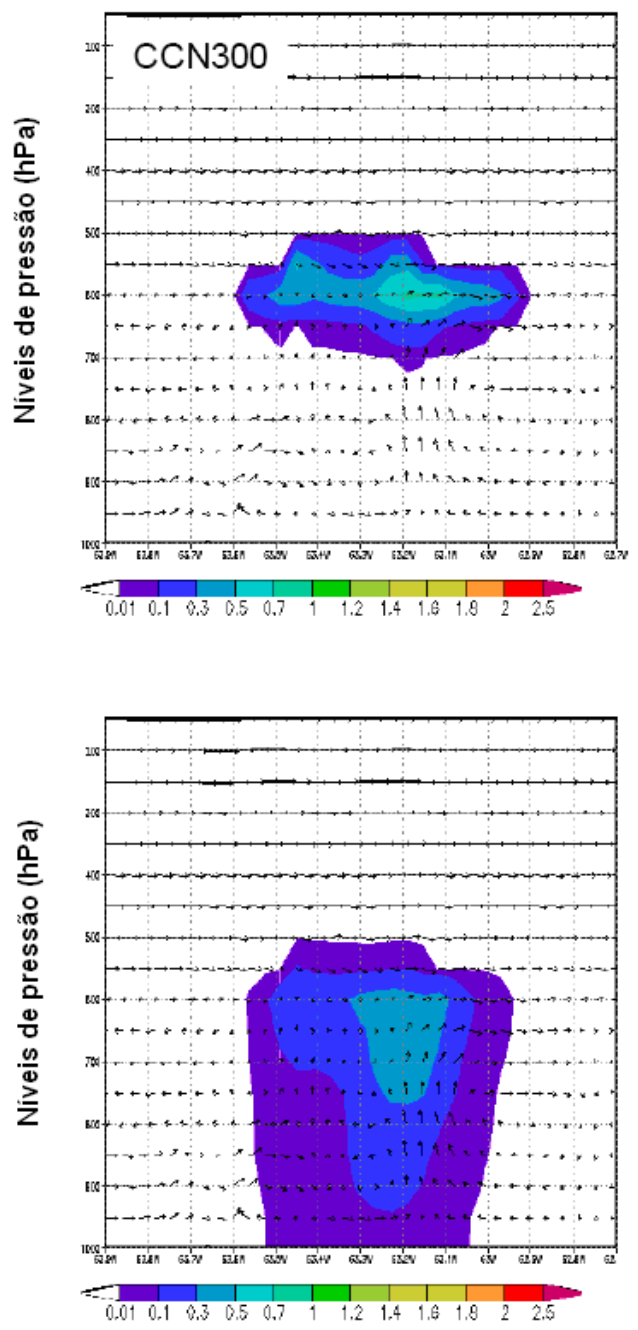

ou implementadas, como as distribuições gama (Ferrier 1994, Walko et al. 1995, Meyers et al. 1997), lognormal (Feingold et al. 1998) e de Weibull. Há indicativos teóricos (Liu et al. 1995; Liu e Hallet, 1998) e experimentais (Costa et al. 2000a) de que esta última, embora não tenha ainda se difundido em modelos numéricos é a que melhor representa populações de gotículas mesmo em diferentes regimes microfísicos. A Tabela 2 mostra as expressões matemáticas para as funções-distribuição citadas (incluindo a exponencial) e as equações para o "diâmetro de escala" ou "declividade" da distribuição. Nas equações mostradas, $\Gamma$ representa a função gama (ou função fatorial), $\mathrm{N}_{\mathrm{t}}$ representa a concentração total de gotículas, $\mathrm{q}_{1}$ o conteúdo de água líquida, $\rho$ w a densidade da água líquida, $v$ o parâmetro de forma da função gama, $\sigma$ o parâmetro de largura do espectro para a distribuição lognormal e $\mu$ o parâmetro de forma da distribuição de Weibull.
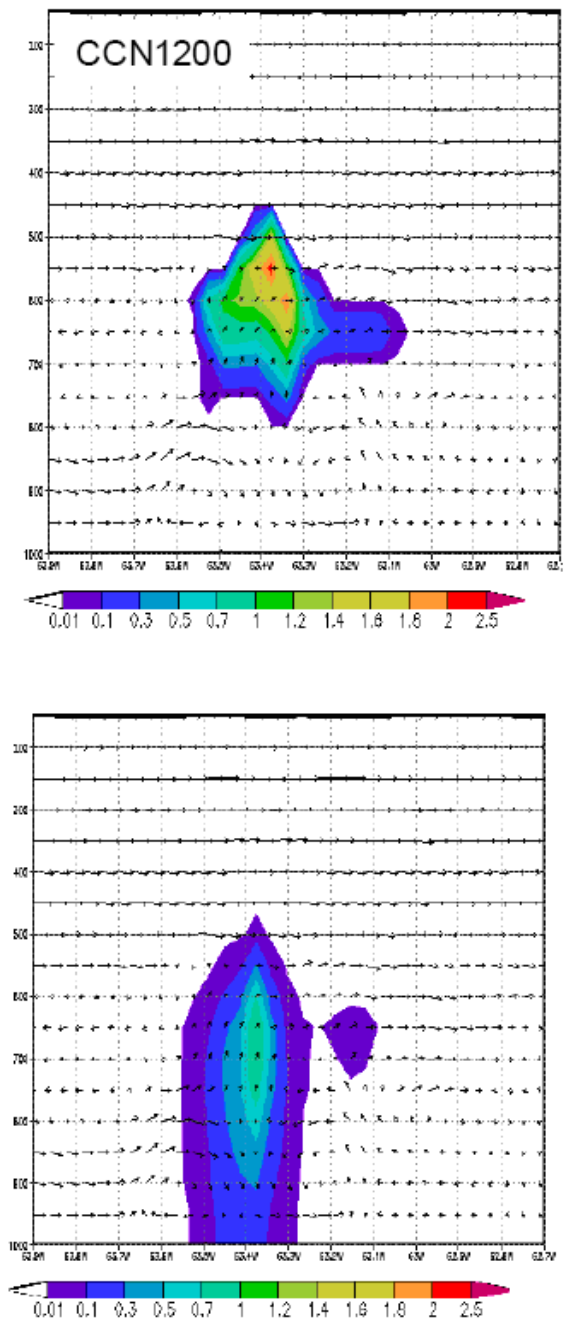

Figura 12 - Razão de mistura de água de nuvem (acima) e de chuva (abaixo) para duas simulações: CCN300 (à esquerda) e CCN1200 (à direita). Adaptado de Martins (2006) e reproduzido com consentimento do autor. 
O uso destas funções de base permite que a equação de coalescência estocástica (que contém um produto de funções de distribuição) seja resolvida, possibilitando que ao menos em parte, se evitem artificialismos como parametrizações do tipo autoconversão-coleta, baseadas em empirismos e simplificações extremas.

Um problema ainda a ser resolvido nas parametrizações que usam funções de base, como a gama, é a escolha do parâmetro de forma, comumente especificado pelo usuário como uma simples constante. Há uma variação significativa nesse parâmetro, relacionada às diferenças entre as massas de ar, à variabilidade interna das nuvens e a seu ciclo de vida. Ajustes de espectros observados para distribuições gama mostram que esse parâmetro varia tipicamente de valores próximos de 1,0 (para os quais a distribuição gama praticamente se reduz à exponencial) até valores muito elevados, de várias dezenas. Alguns autores mostram que é relativamente simples especificar diversos diferentes do parâmetro de forma para diferentes massas de ar, vide Costa et al. (2000a) e Martins (2006). Nestes dois trabalhos, que correspondem respectivamente a observações predominantemente sobre o Nordeste setentrional e a Amazônia, os autores reconheceram que há uma clara tendência de nuvens com maiores concentrações de gotículas apresentarem também espectros mais estreitos, e vice-versa. Assim, ao se usar a distribuição gama como função de base, foram encontrados parâmetros de forma maiores em ambos os casos, na medida em que as concentrações de gotículas cresciam. Uma questão que permanece em aberto, porém, é que não há um mecanismo trivial pelo qual se possam prognosticar as modificações nesse parâmetro associadas a processos de mistura, crescimento condensacional, coalescência, etc.(Costa et al., 2000a).

Com relação a processos microfísicos em nuvens na Amazônia, Martins (2006) investigou a sensibilidade de nuvens e sistemas de nuvens à parâmetros como a concentração de aerossóis, e mostrar que o ciclo de vida dessas nuvens e sistemas pode ser fortemente alterado com mudanças em parâmetros microfísicos. Usando um modelo de mesoescala (RAMS, Pielke et al. 1992, Cotton et al. 2003), com grades aninhadas com resolução explícita dos movimentos convectivos (1 x $1 \mathrm{~km}$ no último nível de aninhamento), o autor simulou a formação de nuvens em diferentes valores/condições de concentração de CCN, IN (núcleos de gelo) e parâmetros de forma. Seus resultados indicaram que o valor máximo de conteúdo de água de nuvem, integrado verticalmente, é até 4 vezes maior nas simulações em que a concentração de $\mathrm{CCN}$ foi quadruplicada, comparativamente àquela representando uma atmosfera limpa, e que a fração de cobertura de nuvens também cresce. Os experimentos com concentrações aumentadas de CCN mostraram taxas de precipitação máxima superiores àquelas encontradas na simulação de atmosfera limpa. Em contrapartida, a precipitação total acumulada é maior neste caso do que nas condições de atmosfera poluída. A Figura 12 ilustra uma comparação entre duas das simulações de Martins (2006), com diferentes concentrações de CCN (300 cm³ e 1200 $\mathrm{cm}^{-3}$ ), evidenciando a presença de valores mais elevados da razão de mistura de água líquida (nuvem e chuva), bem como de precipitações mais localizadas na simulação "CCN1200".

\section{Considerações Finais: Sumário, desafios para a Modelagem de Microfísica de Nuvens e Aerossóis}

Diferentes experimentos de coleta de dados de microfísica (Costa et al., 2000a, Stith et al., 2002, Costa et al. 2002, Andreae et al. 2004) sugerem que as atividades humanas, e as emissões de poluentes associadas, cumprem um papel significativamente relevante na modificação das propriedades de microestrutura das nuvens. Dependendo da magnitude da produção de aerossóis de natureza antrópica (tanto de origem urbana, industrial ou queima de biomassa), tal influência pode ser limitada à escala local (como sugerido pelos resultados

Tabela A.1 - Instrumentação a bordo do ALPA

\begin{tabular}{cc}
\hline Parâmetro Medido & Sensor(es) \\
\hline Temperatura & Rosemount 102AU1AF \\
\hline Pressão Estática & Rosemount 1201F \\
\hline Pressão Dinâmica & Rosemount 1221F \\
\hline Latitude e Longitude & Trimble GPS \\
\hline Temperatura do Ponto de Orvalho & EG\&G 137-C3-S3 \\
\hline Água Líquida & Csiro-King LWC \\
\hline Aerossóis & CCNC UW 83-1 \\
\hline Hidrometeoros & FSSP-100, OAP-200X, OAP-200Y \\
\hline Radiação de Onda Curta & EPPLEY PEP \\
\hline Radiação de Onda Longa & EPPLEY PEP
\end{tabular}


do Experimento do Ceará), como também pode atingir escala regional ou sub-continental (o que pode ser verificado a partir dos dados do LBA-SMOCC-EMfiN!).

Tais mudanças microestruturais respondem por alterações em propriedades macroscópicas das nuvens e sistemas. Nuvens dotadas de maiores concentrações de gotículas são mais "brilhantes", isto é, apresentam uma maior refletividade pelo simples fato de possuírem um maior número de centros de espalhamento de luz. Ao mesmo tempo, por terem uma menor eficiência de precipitação e eventualmente, como é o caso de nuvens convectivas com altas concentrações de gotículas, requererem a participação da fase sólida (formação de cristais de gelo) para produzirem precipitação, nuvens formadas em massas de ar com elevadas concentrações de aerossóis tendem a ter ciclos de vida mais longos. Acrescente-se que nuvens mais profundas, que produzem "bigornas" a partir do desentranhamento de material condensado em altos níveis, atuam bem mais fortemente como limitadores da radiação solar incidente sobre a superfície (teoria que ficou conhecida como a do "termostato de cirros", Ramanathan e Collins, 1991). Os resultados desses experimentos corroboram, assim, com as estimativas globais de um aumento do albedo planetário em associação com a intensificação do efeito indireto dos aerossóis. Suas bases de dados permitem aferir, validar e calibrar modelos de nuvens, cruciais para o desenvolvimento de parametrizações físicas dos processos envolvendo nuvens para modelos de escala global (que, por sua limitada resolução espacial, são incapazes de representar tais processos explicitamente) e, portanto, para inferir que fração do aquecimento global associado aos gasesestufa é efetivamente contrabalançada pelo efeito indireto dos aerossóis, o que ainda se constitui como uma das maiores fontes de incerteza em estudos de mudança climática global.

Durante a campanha do LBA-SMOCC-EMfiN!, entre Setembro e Outubro de 2002, foi possível coletar dados de microfísica de nuvens em uma ampla variedade de condições ambientais, particularmente sobre a Amazônia brasileira, cobrindo um intervalo de concentração de $\mathrm{CCN}$ e de gotículas de nuvens em torno de uma ordem de magnitude, desde o ambiente limpo da costa do Nordeste Brasileiro e do oeste da Amazônia até condições fortemente poluídas, sobre a parte sul da Amazônia e no Brasil central. Nestas últimas regiões, a ocorrência de queimadas no início do período investigado era a principal responsável pela elevação dramática da concentração de aerossóis em geral e de CCN, em particular, com um potencial significativo de modificação das propriedades microfísicas das nuvens sobre a região.

Os estudos realizados indicaram, em geral, que os processos de formação de precipitação na fase quente são fortemente inibidos no ambiente com forte presença de queimadas. Diferenças significativas foram observadas entre as propriedades microfísicas de nuvens sobre as regiões limpas do oeste da Amazônia e nas áreas poluídas por queimadas ao sul. Durante a campanha, as concentrações médias de gotículas de uma região e de outra diferiram por um fator de pelo menos 2, mas usando valores típicos de concentrações de gotículas encontradas durante a campanha do TRMM-LBA para o ambiente limpo (e.g., Stith et al. 2002) e considerando-se a possível subestimação das contagens de gotículas no período das queimadas em virtude de erros de coincidência da FSSP, é bastante provável que essa diferença se aproxime de uma ordem de magnitude.

É evidente que, com diferenças dessa dimensão na concentração de gotículas, e levando-se em conta que o transporte de poluentes produzidos em queimadas assume proporções continentais (Freitas et al., 2005; Sherwood, 2002), o efeito desses aerossóis assume papel significativo, ao ponto de trazer impacto regional, senão global. As medidas in situ (descritas em Andreae et al. 2004 e no presente trabalho) e observações remotas (e.g., Kaufman e Fraser 1997, Rosenfeld, 1999; Rosenfeld e Woodley, 2003) sugerem que o efeito imediato da maior emissão de aerossóis sobre as nuvens é uma redução do desenvolvimento da precipitação na fase quente. As conseqüências das transformações na microestrutura das nuvens ainda não são claramente identificadas, mas é possível que exista um impacto pelo menos em escala regional. Parte das incertezas pode ser reduzida por meio de estudos de modelagem e esforços nesse sentido têm sido empreendidos.

Apesar das limitações dos modelos de parcela, Costa e Sherwood (2005) conseguiram abordar diversas questões relacionadas à convecção amazônica e chegaram a resultados que, em sua maioria, mostram a justeza dos pontos levantados por Andreae et al. (2004). Os autores também mostraram, no entanto, que uma vez que o ciclo das queimadas na Amazônia acompanha o ciclo anual (que influencia parâmetros como a umidade disponível para a formação de nuvens), não é possível se limitar, no estudo da variabilidade sazonal na convecção amazônica, à questão da maior ou menor concentração de núcleos de condensação, e que outros fatores também cumprem papel relevante (CCN gigantes, variabilidade na velocidade vertical e umidade relativa em baixos níveis, particularmente).

Os autores mostram que um pensamento baseado simplesmente no chamado "efeito Twomey" (ou seja, no conteúdo de água líquida adiabático distribuído sobre uma quantidade variável de gotículas de nuvens) só pode ser aplicado em ambientes limpos. Em ambientes poluídos, os resultados do modelo de parcela obtidos por Costa e Sherwood (2005), indicam que a altitude de formação de chuva quente não é governada pelo crescimento geral do diâmetro médio das gotículas, como nos ambientes limpos, mas, ao invés disso, é fortemente influenciada pela largura do espectro. Nas 
simulações efetuadas, o crescimento das partículas maiores via coleta, aparentemente domina o crescimento condensacional na produção de embriões de gotas de chuva no ambiente poluído. Como conseqüência, o sistema se torna mais sensível à presença de GCCN e UCCN, uma vez que esses são responsáveis por nuclear as gotículas maiores que atuam como coletores. Esse não é o caso dos ambientes mais limpos (com concentrações de gotículas abaixo de 700-800 cm-3), nos quais os GCCN e UCCN são irrelevantes para o desenvolvimento da chuva quente, como discutido em trabalhos de outros autores. As simulações de Costa e Sherwood (2005), também indicam que as nuvens poluídas são mais sensíveis à velocidade vertical que as nuvens limpas e que a umidade em baixos níveis, também aparece como um importante fator para modificar a altitude de chuva quente, especialmente em regimes de altas concentrações de gotículas.

Amudança no padrão de desenvolvimento da precipitação associado a modificações no campo de aerossóis na Amazônia, também foi simulada através de outra plataforma de modelagem por Martins (2006): um modelo de nuvens, com representação explícita da estrutura tridimensional do campo de condensado (o que constitui uma superioridade bastante óbvia em relação à ausência de dimensionalidade do modelo de parcela). Os resultados das diferentes plataformas foram convergentes, e sugerem que alterações de natureza antropogênica já são perceptíveis sobre os sistemas de nuvens da Amazônia em associação com as queimadas.

Apesar dos avanços obtidos na compreensão desses processos, é preciso admitir que uma série de desafios ainda se coloca para uma modelagem adequada dos processos microfísicos e que várias questões permanecem em aberto. Ainda é preciso avançar na modelagem das fontes de aerossóis e suas emissões, a fim de que se possa prever melhor a evolução dos $\mathrm{CCN}$ e dos IN. Ainda se conhece pouco a respeito da presença de aerossóis gigantes e de sua possível influência no desenvolvimento da precipitação. Os processos na fase fria ainda carecem de observações apropriadas, visto que apenas medidas realizadas durante a estação chuvosa estão disponíveis (Stith et al. 2002) Por fim, a integração dos diversos processos em plataformas de modelagem mais complexas é crucial para se estimar os efeitos em grande escala das alterações em curso no efeito indireto dos aerossóis.

\section{AGRADECIMENTOS}

Os autores agradecem ao Prof. Dr. Jorge Alberto Martins pela permissão de uso de uma das figuras de sua tese de doutorado. Ambos os autores agradecem ao Conselho Nacional de Desenvolvimento Científico e Tecnológico; o primeiro (Costa) pelo apoio financeiro concedido para o "Experimento de Microfísica de Nuvens" - EMfiN!; o segundo (Pauliquevis) pela concessão de bolsa e apoio via projeto de pesquisa (processo 552831/2006-9).

\section{Apêndice \\ Instrumentação do Avião-Laboratório para Pesquisas Amosféricas da Universidade Estadual do Ceará (ALPA-UECE)}

O ALPA é uma aeronave EMBRAER Bandeirante, modificado para pesquisa, equipado com um sistema de posicionamento global (Global Positioning System, GPS), sensores de pressão estática e dinâmica, temperatura, temperatura do ponto de orvalho e água líquida, um contador de núcleos de condensação de nuvens (Cloud Condensation Nucleous Counter, $\mathrm{CCNC}$ ), e três sondas espectrométricas (Forward-Scattering Spectrometer Probe FSSP-100, Optical Array Probe OAP-200X, and Optical Array Probe OAP-200Y). A Tabela A.1 mostra uma lista detalhada da instrumentação instalada no ALPA.

Dentre os equipamentos listados na Tabela 3, as sondas espectrométricas merecem destaque, uma vez que é através delas que se obtêm dados referentes às funções-distribuição de hidrometeoros. A sonda FSSP classifica gotículas de nuvem por tamanho, em 15 categorias, no intervalo de 2 a $47 \mu \mathrm{m}$. A sonda $200 \mathrm{X}$ conta e classifica gotas no intervalo de $30 \mu \mathrm{m}$ a $450 \mu \mathrm{m}$ de diâmetro, enquanto a sonda $200 \mathrm{Y}$ conta e classifica as gotículas no intervalo de $300 \mu \mathrm{m}$ a $4 \mathrm{~mm}$ de diâmetro. $\mathrm{O}$ uso conjunto das três sondas permite obter funções-distribuição de hidrometeoros varrendo 3 ordens de magnitude em diâmetro.

\section{REFERÊNCIAS}

ALLEY, R. B., MAROTZKE, J., NORDHAUS, W. D., OVERPECK, J. T., PETEET, D. M., PIELKE JR., R. A., PIERREHUMBERT, R. T., RHINES, P. B., STOCKER, T. F., TALLEY, L. D., WALLACE, J. M.: Abrupt Climate Change. Science, v. 299, p. 2005 - 2010, 2003.

ANDREAE, M. O., D. ROSENFELD, P. ARTAXO, A. A. COSTA, G. P. FRANK, K. M. LONGO, AND M. A. F. SILVA-DIAS: Smoking Rain Clouds over the Amazon. Science, v. 303, p. 1337-1342, 2004.

ANDREAE, M. O. , P. ARTAXO, C. BRANDAO, F. E. CARSWELL, P. CICCIOLI, A. L. DA COSTA, A. D. CULF, J. L. ESTEVES, J. H. C. GASH, J. GRACE, P. KABAT, J. LELIEVELD, Y. MALHI, A. O. MANZI, F. X. MEIXNER, A. D. NOBRE, C. NOBRE, M. D. L. P. RUIVO, M. A. SILVA-DIAS, P. STEFANI, R. VALENTINI, J. VON JOUANNE, M. J. WATERLOO: Biogeochemical cycling of carbon, water, energy, trace gases and aerosols in Amazonia: The LBA-EUSTACH experiments. Journal of Geophysical Research, v. 107, 10.1029/2001JD000524 (2002). 
ARTAXO, P., STORMS, H., BRUYNSEELS, F., VANGRIEKEN, R., AND MAENHAUT, W.: Composition and sources of aerosols from the Amazon Basin, Journal of Geophysical Research (Atmospheres), v. 93 (D2), p. 1605-1615, 1988.

ARTAXO, P., MAENHAUT, W., STORMS, H., AND VANGRIEKEN, R.: Aerosol characteristics and sources for the Amazon Basin during the wet season, Journal of Geophysical Research (Atmospheres), v. 95 (D10), p. 16 971- 16 985, 1990.

ARTAXO, P., MARTINS, J. V., YAMASOE, M. A., PROCOPIO, A. S., PAULIQUEVIS, T. M., ANDREAE, M. O., GUYON, P., GATTI, L. V., AND LEAL, A. M. C.: Physical and chemical properties of aerosols in the wet and dry seasons in Rondonia, Amazonia, Journal of Geophysical Research (Atmospheres), v. 107, 8081, doi: 10.1029/2001JD000666, 2002.

BAKER, M. B., PETER, T.: Small-scale cloud processes and climate. Nature, v. 451, p. 299-300, 2008.

BERRY, E. X.: Cloud drop growth by coalescence. Journal of the Atmospheric Sciences, v. 24, p. 688-701, 1967.

BERRY, E. X., REINHARDT, R. L.: An analysis of cloud drop growth by collection. Part I: double distribution. Journal of the Atmospheric Sciences, v. 31, p. 1814-1824, 1974a.

BERRY, E. X., REINHARDT, R. L.: An analysis of cloud drop growth by collection. Part I: double distribution. Journal of the Atmospheric Sciences, v. 31, p. 1825-1831, $1974 b$.

BRENGUIER, J.-L.: Coincidence and Dead-Time Corrections for Particles Counters. Part II: High Concentration Measurements with an FSSP. Journal of Atmospheric and Oceanic Technology, v. 6, p. 585-598, 1989.

BREÓN, F.-M.: How Do Aerosols Affect Cloudiness and Climate? Science, v. 313. p. 623 - 624, 2006.

CHEN, J.-P., G. M. MCFARQUHAR, A. J. HEYMSFIELD, V. RAMANATHAN: A modeling and and observational study of the detailed microphysical structure of tropical cirrus anvils. Journal of Geophysical Research, v. 102, 6637-6653, 1997.

CHUANG, C. C., PENNER, J. E., PROSPERO, J. M., GRANT, K. E., RAU, G. H., KAWAMOTO, K.: Cloud susceptibility and the first aerosol indirect forcing: Sensitivity to black carbon and aerosol concentrations, Journal of Geophysical Research, v. 107(D21), Artigo no. 4564, doi:10.1029/ 2000JD000215, 2002.

COOPER, W. A.: Effects of coincidence on measurements with a Forward Scattering Spectrometer Probe. Journal of Atmospheric and Oceanic Technology, v. 5, p. 823-832, 1988.

COSTA, A. A., C. J. DE OLIVEIRA, J.C.P. DE OLIVEIRA, A. J. C. SAMPAIO: Microphysical Observations of Warm Cumulus Clouds in Ceará, Brazil. Atmospheric Research, v. 54, 167-199, 2000a.
COSTA, A. A., G. P. ALMEIDA., A. J. C. SAMPAIO: A binmicrophysics cloud with high-order, positive-definitive advection, Atmospheric Research, v. 55, p. 225-255, $2000 b$

COSTA, A. A., COTTON, W. R., WALKO, R. L., PIELKE, R. A., Coupled ocean-cloud-resolving simulations of the air-sea interaction over the western Pacific. Journal of the Atmospheric Sciences, v. 58, p. 3357-3375, 2001a.

COstA, A. A., COTTON, W. R., WALKO, R. L., PIELKE, R. A., JIANG, H., SST sensitivities in multi-day TOGA COARE simulations. Journal of the Atmospheric Sciences, v. 58, p. 253-268, $2001 \mathrm{~b}$.

COSTA, A. A., SHERWOOD, S.. Parcel model simulations of aerosol warm phase cloud microphysics interactions over the Amazon. Atmospheric Chemistry and Physics Discussion, v. 5, p. 481-508, 2005.

COTTON, W. R., PIELKE, R. A., WALKO, R. L., LISTON, G. E., TREMBACK, C., JIANG, H., MCANELLY, R. L., HARRINGTON, J. Y., NICHOLLS, M. E., CARRIO, G. G., MCPHADDEN, J. P.: RAMS 2001: Current status and future directions. Meteorology and Atmospheric Physics, v. 82, p. 5-29, 2003.

DECESARI, S., FUZZI, S., FACCHINI, M. C., et al.: Characterization of the organic composition of aerosols from Rondônia, Brazil, during the LBA-SMOCC 2002 experiment and its representation through model compounds. Atmospheric Chemistry and Physics, v. 6, p. 375-402, 2006.

FEINGOLD, G., R. L. WALKO, B. STEVENS, W. R. COTTON: Simulations of marine stratocumulus using a new microphysical parameterization scheme. Atmospheric Research, v. 47-48, p. 505-528, 1998.

FERRIER, B. S.,: A double-moment multiple-phase fourclass bulk ice scheme. Part I: Description. Journal of the Atmospheric Sciences, v.51, p. 249-280, 1994.

FOREST, C. E., STONE, P. H., SOKOLOV, A. P., ALLEN, M. R., AND WEBSTER, M. D.: Quantifying uncertainties in climate system properties with the use of recent climate observations, Science, v. 295, p. 113-117, 2002.

FREITAS S. R., K. LONGO, M. SILVA DIAS, P. SILVA DIAS, R. CHATFIELD, E. PRINS, P. ARTAXO, G. GRELL, F. RECUERO: Monitoring the transport of biomass burning emissions in South America. Environmental Fluid Mechanics, DOI: 10.1007/s10652-005-0243-7, v. 5, p. 135 - 167, 2005.

FREUD, E., ROSENFELD, D., ANDREAE, M. O., COSTA, A. A., ARTAXO, P.: Robust relations between $\mathrm{CCN}$ and the vertical evolution of cloud drop size distribution in deep convective clouds. Atmospheric Chemistry and Physics, v. 8, p. 1661-1675, 2008 
FUZZI, S., DECESARI, S., FACCHINI, M. C., et al.: Overview of the inorganic and organic composition of size-segregated aerosol in Rondônia, Brazil, from the biomass-burning period to the onset of the wet season, Journal of Geophysical Research, 112, D01201, doi:10.1029/2005JD006741, 2007.

GRABOWSKI, W. W.,: Impact of cloud microphysics on convective-radiative quasi equilibrium revealed by cloudresolving convection parameterization, Journal of Climate, v. 16, p. 3463-3475, 2003.

HOUGHTON, J. T., DING, Y., GRIGGS, D. J., NOGUER, M., VAN DER LINDEN, P. J., DAI, X., MASKELL, K., JOHNSON, C. A. (editores): Climate Change 2001: The Scientific Basis: Contribution of Working Group I to the Third Assessment Report of the Intergovernmental Panel on Climate Change (Climate Change 2001). Cambridge University Press, Cambridge. 2001. 881 pp.

IPCC: Summary for Policymakers. In: Climate Change 2007: The Physical Science Basis. Contribution of Working Group I to the Fourth Assessment Report of the Intergovernmental Panel on Climate Change [Solomon, S., D. Qin, M. Manning, Z. Chen, M. Marquis, K.B. Averyt, M.Tignor and H.L. Miller (eds.)]. Cambridge University Press, Cambridge, United Kingdom and New York, NY, USA, 2007.

JOHNSON, D. B.: The Role of Giant and Ultragiant Aerosol Particles in Warm Rain Initiation, Journal of the Atmospheric Sciences, v. 39, p. 448-460, 1982.

KAUFMAN, Y. J., R. S. FRASER: The effect of smoke particles on clouds and climate forcing. Science, v. 277, p. 16361639, 1997.

KAUFMAN, Y. J., P. V. HOBBS, V. W. J. H. KIRCHOFF, P. ARTAXO, L. A. REMER, B. N HOLBEN, M. D. KING, D. E. WARD, E. M. PRINCE, K. M. LONGO, L. F. MATTOS, C. A. NOBRE, J. D. SPINHIRNE, Q. JI, A. M. THOMPSON, J. F. GLASON, S. A. CHRISTOPHER, S. C. TSAY: Smoke, clouds and radiation - Brazil (SCAR-B) experiment. Journal of Geophysical Research, v. 103, p. 31783-31808, 1998.

KAUFMAN, Y. J., TANRE, D., BOUCHER, O.:A satellite view of aerosols in the climate system. Nature, v. 419, p. 215-223, 2002.

KAUFMAN, Y. J., KOREN, I.: Smoke and pollution aerosol effect on cloud cover. Science, v. 313, p. 655-658, 2006.

KESSLER, E.: On the distribution and continuity of water substance in atmospheric circulation. Meteorological Monographs, v. 32, 84pp, American Meteorological Society, 1969.

KHAIN, A. P., A. POKROVSKY, I. SEDNEV: Effects of cloud-aerosol interaction on cloud microphysics, precipitation formation and size distribution of atmospheric aerosol particles: numerical experiments with a spectral microphysics cloud model. Atmospheric Research, v. 52, p. 195-220, 1999.

KNOLlENBERG, R. G., KELlY, K., WILSON, J. C.,: Measurements of high number densities of ice crystals in the tops of tropical cumulonimbus. Journal of Geophysical Research, v. 98, p. 8639-8664, 1993.

KOGAN, Y. L.: The simulation of a convective cloud in a 3-D model with explicit microphysics. Part I: Model description and sensitivity experiments. Journal of the Atmospheric Sciences, v. 48, p. 1160-1189, 1991.

LEVITUS, S., ANTONOV, J. I., WANG, J., DELWORTH, T. L., DIXON, K. W., BROCCOLI, A. J.: Anthropogenic Warming of Earth's Climate System. Science, v. 292, p. 267-270, 2001.

LIU, Y., L. YOU, W. YANG, F. LIU, On the size distribution of cloud droplets, Atmospheric Research, v. 35, p. 201-216, 1995.

LIU, Y. J. HALLETT: On Size Distributions of Cloud Droplets Growing by Condensation: A New Conceptual Model. Journal of the Atmospheric Sciences, v. 55, p. 527-536, 1998.

LOHMANN, U., FEICHTER J. Global indirect aerosol effects: a review, Atmospheric Chemistry and Physics, vol. 5, p. 715-737, 2005.

LYNN B., A. KHAIN, J. DUDHIA, D. ROSENFELD, A. POKROVSKY, A. SEIFERT: Spectral (bin) microphysics coupled with a mesoscale model (MM5). Part 2: Simulation of a CaPe rain eventwith squall line. Monthly Weather Review, v. 133, p. 59-71, 2005.

MARTINS, J.A.: Efeito dos núcleos de condensação na formação de nuvens e o desenvolvimento da precipitação na região amazônica durante a estação seca. Tese de Doutorado - Universidade de São Paulo, 2006.

MEYERS, M. P., R. L. WALKO, J. Y. HARRINGTON, W. R. COTTON: New RAMS cloud microphysics parameterization. Part II: The two-moment scheme. Atmospheric Research, v. 45, p. 3-39, 1997.

NENES A., S. GHAN, H. ABDUL-RAZZAK, P. Y. CHUANG, J. H. SEINFELD: Kinetic limitations on cloud droplet formation and impact on cloud albedo. Tellus B, v. 53, p. 133-149, 2001.

NENES, A., CHARLSON, R. J., FACCHINI, M. C., KULMALA, M., LAAKSONEN, A., AND SEINFELD, J. H.: Can chemical effects on cloud droplet number rival the first indirect effect?, Geophys. Res. Lett., 29 (17), art. no. 1848, doi:10.1029/2002GL015295, 2002.

PAULIQUEVIS, T., L. L. LARA, M. L. ANTUNES, AND P. ARTAXO, Aerosol and precipitation chemistry in a remote site in Central Amazonia: the role of biogenic contribution, Atmos. Chem. Phys. Discuss., 7, 1-45, 2007. 
PIELKE, R. A., COTTON, W. R., WALKO, R. L., TREMBACK, C. J., LYONS, W. A1,. GRASSO, L. D., NICHOLLS, M. E., MORAN, M. D., WESLEY, D. A., LEE, T. J., COPELAND, J. H.: A comprehensive meteorological modeling system - RAMS. Meteorology and Atmospheric Physics, v. 49, p. 69-91, 1992.

RAMANATHAN, V., COLLINS, W.: Thermodynamic regulation of ocean warming by cirrus clouds deduced from observations of the 1987 El Niño. Nature, v. 351, p. 27-32, 1991.

RAMANATHAN, V., CRUTZEN, P. J., KIEHL, J. T. , ROSENFELD, D.: Atmosphere - Aerosols, climate, and the hydrological cycle. Science, v. 294, p. 2119-2124, 2001.

ROBERTS, G.C., NENES, A., SEINFELD, J. H., ANDREAE, M. O.: Impact of biomass burning on cloud properties in the Amazon Basin, J Geophys Res, v. 108 (D2), Art. No. 4062, doi:10.1029/2001JD000985, 2003.

ROSENFELD, D. TRMM observed first direct evidence of smoke from forest fires inhibiting rainfall. Geophysical Research Letters, v. 26, p. 3105-3108, 1999.

ROSENFELD, D., W. L. WOODLEY, 2003: Spaceborne inferences of cloud microstructure and precipitation processes: Synthesis, insights, and implications. Meteorological Monographs. Vol. 29, 59-59.

ROTSTAYN, L.D., LOHMANN, U.: Tropical Rainfall Trends and the Indirect Aerosol Effect., Journal of Climate, v. 15, p. 2103-2116, 2002.

SANTOS, A. C. S., COSTA, A. A., OLIVEIRA, J. C. P., CAMPOS FILHO, M. C.: Estudo De Caso Da Variabilidade
De Parâmetros Microfísicos Em Nuvens Da Amazônia. Revista Brasileira de Meteorologia, v. 17, p. 141-151, 2002.

SHERWOOD, S.C: A microphysical connection among biomass burning, cumulus clouds, and stratospheric moisture. Science, v. 295, p. 1272-1275, 2002.

STITH J. L., J. E. DYE, A. BANSEMER, A. J. HEYMSFIELD, C. A. GRAINGER, W. A. PETERSEN, R. CIFELLI: Microphysical observations of tropical clouds. J. Appl. Meteor., v. 41, p. 97-117, 2002.

VITOUSEK, P. M., MOONEY, H.A., LUBCHENCO, J. , MELILLO, J. M.: Human domination of Earth's ecosystem. Science, v. 277, p. 494-499, 1997.

WALKO, R. L, COTTON, W. R., HARRINGTON, J. L., MEYERS, M. P.: New RAMS cloud micro-physics parameterization. Part I: The single-moment scheme. Atmospheric Research, v. 38, p. 29-62, 1995.

WIELICKI, B. A., WONG, T., LOEB, N., MINNIS, P., PRIESTLEY, K., KANDEL, R.: Changes in Earth's Albedo Measured by Satellite. Science. v. 308, p. 825, 2005.

YIN, Y., Z. LEVIN, T. G. REISIN, S. TZIVION: The effects of giant cloud condensation nuclei on the development of precipitation in convective clouds - a numerical study. Atmospheric Research, v. 53, p. 91-116, 2000.

YIN, Y., S. WURZLER, Z. LEVIN, T. G. REISIN: Interactions of mineral dust particles and clouds: Effects on precipitation and cloud optical properties. J. Geophys. Res., Art. No. 4724, 2002.

ZWIERS, F.W., WEAVER, A.J.: The causes of 20th century warming. Science, v. 290, p. 2081-2083, 2000. 